NOTICE: this is the author's version of a work that was accepted for publication in Construction and Building Materials. Changes resulting from the publishing process, such as peer review, editing, corrections, structural formatting, and other quality control mechanisms may not be reflected in this document. Changes may have been made to this work since it was submitted for publication. A definitive version was subsequently published in CONSTRUCTION AND BUILDING MATERIALS, VOL 23, (1), 2009, http://dx.doi.org/10.1016/j.conbuildmat.2008.01.009 


\title{
Tensile strain hardening behaviour of hybrid steel-polyethylene fibre reinforced cementitious composites
}

\author{
S.F.U. Ahmed ${ }^{1 *}$ and M. Maalej ${ }^{2}$ \\ ${ }^{1}$ Connell Wagner Pty Ltd, Level 1, 256 Adelaide Terrace, Perth, WA 6000, Australia. \\ ${ }^{2}$ Dept. of Civil and Environmental Engineering, University of Sharjah, Sharjah, PO Box \\ 27272 , UAE
}

\begin{abstract}
:
Tensile strain hardening and multiple cracking behaviours of fibre reinforced cementitious composites containing different hybrid combinations of steel (ST) and polyethylene (PE) fibres are reported. Various hybrid combinations of ST and PE fibres of $12 \mathrm{~mm}$ length are studied. Different hybrid combinations of ST and PE fibres of 18 mm length are also studied here. The effects of addition of different types of sands of different contents on the strain hardening behaviour are also evaluated. PE fibres are found to improve the tensile strain capacity of hybrid fibre composites whereas ST fibres contributed on the improvement of ultimate tensile strength of hybrid fibre composites. By increasing the length of PE fibres by 1.5 times significant increase in tensile strain capacity as well as improvement in strain hardening and multiple cracking behaviour of hybrid fibre composites is observed. The addition of sand adversely affected the strain hardening and multiple cracking behaviour of hybrid fibre composites with reduction in tensile strain capacity.
\end{abstract}

Keywords: Hybrid fibres, strain hardening, multiple cracking, tension.

*Corresponding author, tel. +61 892231570 , Fax: +61 892231605

Email: AhmedS@conwag.com (S.F.U.Ahmed) 


\section{Introduction}

Fibre reinforced cementitious composites (FRCC) with tensile strain hardening and multiple cracking behaviour have already been developed $[1,2]$. The unique feature of these composites is the closely spaced multiple cracks the width of which are generally much smaller than that of ordinary fibre reinforced concrete. Most of the strain hardening FRCC is limited to single fibre type [2-7]. Recently, hybrid fibre reinforced cementitious composites exhibiting strain hardening behaviour are also developed [8-12]. In hybrid fibre composites, two or more different types of fibres are suitably combined to exploit their unique properties. The hybridization of fibres in FRCC can be done in different ways, such as by combining different lengths, diameters, modulus and tensile strengths of fibres. Large macro fibres bridge the big cracks and provide toughness, while small micro fibres enhance the response prior or just after the cracking. Micro fibres also improve the pull out response of macro fibres, thus produce composites with high strength and toughness. Mono fibre composites containing high stiffness fibres normally show high ultimate strength, low strain capacity and small crack width properties, while those containing low stiffness fibres show low ultimate strength, high strain capacity and large crack width properties. A hybrid composite, with proper volume ratio of high and low stiffness fibres, can be expected to show simultaneous improvement in ultimate strength, strain capacity and crack width properties.

In this study, experimentally observed tensile strain hardening and multiple cracking behaviour of hybrid steel (ST) - polyethylene (PE) fibre reinforced cementitious composites is reported. In the first part, different hybrid combinations of ST and PE fibres are studied. The superior performance of PE fibres over ST fibres in strain 
hardening and multiple cracking behaviour of hybrid fibre composites is observed. The effect of increase in length of PE fibre on the strain hardening behaviour of hybrid fibre composites are also evaluated here. In the second part of the study, the effects of addition of different sizes of sands with different sand/binder ratios on the strain hardening behaviour are evaluated.

\section{Experimental program}

Details of the five series of experiments performed in the first part of the study are shown in Table 1. The first series comprises mono fibre (ST or PE) composites. In the second series, $0.5 \% \mathrm{ST}$ and different volume fractions of PE fibres were combined. In the third and fourth series different volume fraction of PE fibres were combined with $1.0 \%$ ST and 1.5\% ST fibres, respectively. In second, third and fourth series the length of PE fibres were limited to $12 \mathrm{~mm}$ while the fifth series used $18 \mathrm{~mm}$ PE fibres.

Table 2 shows the experimental program where the effect of addition of sand on the strain hardening and multiple cracking behaviour was studied. Three hybrid fibre composites which exhibited strain hardening and multiple cracking behaviour in the first were considered in the second part of this study where 425 micrometer sand with sand/binder ratio of 0.5 was used in the matrix.

For all series, three prismatic plate specimens of $300 \times 75 \times 15 \mathrm{~mm}$ in dimensions were cast and cured for approximately 28 days in fog room. All specimens were tested in uni-axial tension under displacement control using an Instron testing machine with hydraulic wedge grips. The displacement rate was $0.25 \mathrm{~mm} / \mathrm{min}$. Aluminum plates were epoxy glued onto the ends of the specimens to facilitate gripping. Care was taken to 
ensure proper alignment of the specimens with the machine hydraulic grips. The Instron machine had a fully digital control panel and software to automatically run the tests and collect the load and actuator displacement data. In addition, two LVDTs connected to a data acquisition system were used to measure displacements between two points on the specimen with a gauge length of $140 \mathrm{~mm}$ (Fig. 1) A schematic of the tension test setup is shown in Fig. 1. Resulting load versus crack opening displacement data were recorded and tensile stress versus strain curves were plotted.

\section{Materials and mix proportions}

The cement used in this study was ordinary Portland cement which corresponds to ASTM type I. The physical properties and chemical analysis of cement and silica fume are given in Table 3. The sand used in this study is fine silica sand with maximum size of 425 micrometers. Properties of steel and polyethylene (PE) fibres are shown in Table 4. The steel fibres used in this study were straight and of circular cross section. The mix proportions are given in Tables 1 and 2. The mono and hybrid fibre composites were manufactured in a Hobart mixture.

\section{Results and discussion}

\subsection{Strain hardening and multiple cracking behaviour of mono and hybrid fibre composites}

Fig. 2 shows the tensile strain hardening responses of mono fibre composites. The mono fibre composites with $1.8 \%$ or $2 \%$ ST fibres show high tensile strength but low strain capacity at peak load. On the other hand, the mono fibre composites with $1.8 \%$ or $2 \%$ PE fibres shows low tensile strength but high strain capacities at peak load. The high tensile strength and low strain capacity at peak load of composites with ST fibres are due 
their high modulus while the low tensile strength and high strain capacity at peak load of composites with PE fibres are due to their low modulus.

In Fig. 3 the tensile strain hardening responses of mono and hybrid fibre composites with total fibre volume fractions of $2.0 \%$ is shown. The hybrid fibre composites can be seen to lie between those of ST and PE mono fibre systems. Specifically, the tensile strength of hybrid fibre composites is found to be higher than that of the composite with PE fibres alone, while the tensile strain capacity at peak load is found to be higher than that of the composite with ST fibres alone.

\subsection{Influence of PF fibres on the strain hardening behaviour}

Fig. 4 shows the tensile strain hardening responses of hybrid fibre composites containing $0.5 \%$ ST fibres and various volume fractions of PF fibres ranged between $0.2 \%$ and $1.8 \%$. All hybrid fibre composites exhibited strain hardening behaviour. The composite with $0.5 \% \mathrm{ST}$ and $0.2 \%$ PE fibres exhibited very low tensile strain capacity. All composites showed multiple cracks as shown in Fig. 5 except the composite with $0.5 \% \mathrm{ST}$ and $0.2 \%$ PE fibres where the number of multiple cracks is limited to three. The low strain capacity and limited number of cracks in that composite could be attributed to the low volume fraction of PE fibres which is less than the critical fibre volume fraction for strain hardening behaviour $[9,13]$. The influence of PE fibres on the tensile strain capacity at peak load and ultimate tensile strength of hybrid fibre composites is shown in

Fig. 6. The figure shows that the strain capacity of hybrid fibre composites increases with increase in PE fibres content. The number of multiple cracks also increases with increase in PE fibres content (Fig. 5) i.e. with increase in strain capacity. The hybrid fibre 
composite with $0.5 \% \mathrm{ST}$ and $1.8 \% \mathrm{PE}$ deviated from this trend, probably due to high volume fraction of PE fibres used in the composite resulted in poor dispersion of fibres in the hybrid composite. This can also be seen from Fig. 5 that the number of multiple cracks is also less than that of hybrid composites with $0.5 \% \mathrm{ST}$ and $1.5 \% \mathrm{PE}$ fibres. This suggests the existence of maximum quantity of PE fibres for hybrid combination with $0.5 \%$ ST fibre. The ultimate tensile strength of hybrid fibre composites increases with increase in PE fibre contents (Fig. 6).

The improvement of tensile strain capacity of hybrid fibre composites with increase in the volume fraction of PE fibres can also be seen in Figs. 7 and 10. In Fig. 7 the tensile strain hardening responses of hybrid fibre composites with $1.0 \%$ ST and different volume fractions of PE fibres are shown while those with $1.5 \%$ ST and different volume fractions of PE fibres are shown in Fig. 10. All hybrid fibre composites exhibited strain hardening and multiple cracking behaviour (Figs. 8 and 11). However, the composites with $1.0 \%$ ST and $0.2 \%$ PE fibres and $1.5 \%$ ST and $0.1 \%$ PE fibres exhibited very low tensile strain capacity together with fewer numbers of cracks. The low strain capacity and limited number of cracks observed in both composites could, once again, be attributed to the insufficient amount of PE fibres which is less than the critical volume fraction of fibres $[9,13]$.

The effects of increase of PE fibres content on the improvement of tensile strain capacity at peak load in ST-PE hybrid composites are also observed in Figs. 9 and 12. In Figs. 9 and 12 the variation of tensile strain capacity at peak load and ultimate tensile strength of hybrid fibre composites with different volume fractions of PE and 1\% ST and 
those containing different volume fractions of PE and 1.5\% ST fibres, respectively are shown.

The above results show that the tensile strain capacity at peak load of ST-PE hybrid fibre composites is significantly influenced by the PE fibres. It can also be observed that the PE fibres influenced on the development of ultimate tensile strength of ST-PE hybrid fibre composites where relatively low volume fraction of ST fibres are used (such as at $0.5 \%$ ST fibres) contrary to hybrid composites with higher amount of ST fibres (used such as $1.5 \%$ ST fibres) where negligible increase in ultimate tensile strength is observed. The above results, within the limited hybrid combinations of ST and PE fibres studied in this study, also show that there are maximum limits of PE fibres content for ST-PE hybrid fibre composites and beyond which no improvement in the tensile strain hardening and multiple cracking behaviour is observed. This may be due to the poor dispersion of fibres in the composites during mixing because of excessive amount of PE fibres.

\subsection{Influence of ST fibres on the strain hardening behaviour}

The effects of ST fibres content on the ultimate tensile strength and strain capacity at peak load of hybrid fibre composites are shown in Figs. 13 and 14. It can be seen by observing both figures that the ultimate tensile strength of hybrid fibres composites increases with increase in ST fibres contents. However, no clear relationship between tensile strain capacity at peak load and volume fractions of ST fibres in hybrid fibre composites is observed. 


\subsection{Influence of length of PF fibres on the strain hardening behaviour}

The tensile strain hardening behaviour of hybrid fibre composites with different volume fractions of ST and PE fibres of $18 \mathrm{~mm}$ length is shown in Fig. 15. The tensile strain capacity at peak load increases with increase in volume fractions of PE fibres of $18 \mathrm{~mm}$ length. The number of multiple cracks also increases with increase in volume fractions of PE fibres of $18 \mathrm{~mm}$ length (Fig. 18). The effect of increase in length of PE fibre on the strain hardening behaviour of hybrid fibre composites are shown in Figs. 16 and 17. Both figures show that the strain hardening behaviour with significant increase in strain capacity can be achieved when the length of PE fibres is increased by 1.5 times. Fig. 17 clearly shows that strain hardening behaviour can be achieved in hybrid fibre composites with $1.0 \% \mathrm{ST}$ and $0.25 \%$ PE fibre of $18 \mathrm{~mm}$ length compared to hybrid fibre composites with $1.0 \%$ ST and $0.20 \%$ PE fibre of $12 \mathrm{~mm}$ length where no strain hardening behaviour is observed. The beneficial effect of increase in length of PE fibres on the multiple cracking behaviour can also be confirmed by comparing Figs. 5(c) and 18(b) and Figs. 8(a) and 18(a). The comparison of Figs. 5(c) and 18(b) shows that number of multiple cracks increases significantly by increasing the length of PE fibres by 1.5 times. Similar behaviour can also be seen by comparing Figs. 8(a) and 18(a). This can be attributed to the longer length of PE fibres. Because of their longer length the PE fibres bridged the macro cracks and improved the tensile strain capacity and multiple cracking behaviour. In hybrid fibre composites, where hybridization is done based on fibre dimensions, with different types of long and short fibres, the longer fibres bridge the macro (bigger) cracks and therefore substantially improve the ductility of the composite [14]. The developed micromechanics based model for the design of strain hardening and multiple cracking 
behaviour [9] of hybrid fibre composites, which is briefly described in the manuscript, also shows that by increasing the length of PE fiber by about 1.5 times the strain hardening behaviour is improved where the ratio of ultimate bridging strength to first crack strength $\left(\sigma_{\mathrm{cu}} / \sigma_{\mathrm{fc}}\right)$ increase from 1 to 1.4 . By increasing the gap between $\sigma_{\mathrm{cu}}$ and $\sigma_{\mathrm{fc}}$ the condition for strain hardening in the composite can be promoted.

\subsection{Effects of addition of sand on the strain hardening behaviour}

The effect of addition of sand on the tensile strain hardening behaviour is shown in Fig. 19. Fig. 19(a) shows the strain hardening behaviour of hybrid fibre composites containing $0.5 \% \mathrm{ST}$ and $1.3 \% \mathrm{PE}$ fibres with sand/binder ratio of 0.5 . The figure shows that the strain capacity of the composites is reduced significantly when sand is added although the ultimate tensile strength is increased. The adverse effect of addition of sand on the multiple cracking behaviour of hybrid fibre composites can also be observed by comparing Figs. 5(d) and 20(a) where significant reduction in number of multiple cracks in hybrid fibre composites containing sand can be seen. Similar behaviours are also observed in case of hybrid fibre composites containing 1.0\% ST and $0.8 \%$ PE fibres and 1.5\% ST and $0.5 \%$ PE fibres. The adverse effect of addition of sand on the strain hardening and multiple cracking behaviour of hybrid fibre composites can be attributed to the increase of matrix's fracture toughness due to the addition of sand in the cement paste. It is well established that high sand content resulted in a higher matrix fracture toughness, which in tern increases the first cracking strength of the composite compared to the maximum bridging stress of the fibres; as a result, the condition for strain hardening is violated $[15,16]$. 


\section{Conclusions}

Strain hardening and multiple cracking behaviour of hybrid fibre composites containing different volume fractions of ST and PE fibres of $12 \mathrm{~mm}$ length are reported. PE fibres influenced the tensile strain capacity of hybrid fibre composites. The ultimate tensile strain capacity at peak load is found to increase with increase in PE fibre contents and beyond a particular PE fibre content the strain capacity is decreased. ST fibres, however, contributed in the ultimate tensile strength of hybrid fibre composites. Significant improvement in the strain hardening and multiple cracking behaviour as well as in the strain capacity of hybrid fibre composites are observed when the length of PE fibres is increased by 1.5 times. The addition of sand adversely affected the tensile strain hardening and multiple cracking behaviour of hybrid fibre composites.

\section{References}

[1] Li, V.C. 2003 On Engineered cementitious composites: A review of the material and its applications. Journal of Advanced Concrete Technology, 1(3): 215-230.

[2] Naaman, A.E. 2003 Engineered steel fibres with optimal properties for reinforcement of cement composites, Journal of Advanced Concrete Technology, 1(3): 241-252.

[3] Kanda, T and Li, V.C. 1999. New micromechanics design theory for pseudo strain hardening cementitious composites. Journal of Engineering Mechanics, ASCE, 125(4):373-381. 
[ 4] Kanda, T, Lin, Z. and Li, V.C. 2000. Tensile Stress-Strain Modeling of Pseudo Strain-Hardening Cementitious Composite. Journal of Materials in Civil Engineering, ASCE, 12(2):147-156.

[5] Li, V.C., Wang, S. and Wu, C. 2001. Tensile Strain Hardening Behaviour of Polyvinyl Alcohol Engineered Cementitious Composites (PVA-ECC). ACI Materials Journal, 98(6): 483-492.

[6] Li, V.C., Wu, H.C., Maalej, M., Mishra, D.K., Hashida, T. 1996. Tensile Behaviour of Engineered Cementitious Composites with Discontinuous Random Steel Fibres. Journal of American Ceramic Society, 79(1): 74-78.

[ 7] Kanda, T. and Li, V.C. 2006 Practical design criteria for saturated pseudo strain hardening behaviour in ECC. Journal of Advanced Concrete Technology, 4(1): 5972.

[ 8] Ahmed, S.F.U. Maalej, M. and Paramasivam, P. 2003. Strain-hardening Behaviour of Hybrid Fibre Reinforced Cement Composites. Journal of Ferrocement 33 (3): 172-182.

[ 9] Ahmed, S.F.U., Maalej, M. and Paramasivam, P. 2006. Analytical Model for Tensile Strain Hardening and Multiple Cracking Behaviour of Hybrid Fibre Engineered Cementitious Composites. ASCE, Journal of materials in civil engineering, (In Press).

[10] Kawamata, A., Mihashi, H. and Fukuyama, H. 2002. Material design of hybrid fibre reinforced cementitious composites. Journal of Advanced Concrete Technology, 1(3): 283-290. 
[11] Otsuka, K., Mihashi, H., Mori, S. and Kawamata, A. 2003 Observation of multiple cracking in hybrid FRCC at micro and meso levels, Journal of Advanced Concrete Technology, 1(3): 291-298.

[12] Ahmed, S.F.U. Maalej, M. and Paramasivam, P. 2006. Flexural responses of hybrid steel-polyethylene fibre reinforced cement composites containing high volume fly ash. Journal of construction and building materials (In Press).

[ 13] Li, V.C., and Leung, C.K., 1992 "Steady state and multiple cracking of short random fiber composites", ASCE Journal of Engineering Mechanics,118 (18), 2247-2264.

[14] Banthia, N. and Gupta, R. 2004 Hybrid fiber reinforced concrete (HyFRC): fiber synergy in high strength matrices, Materials and Structures, 37, pp. 707-716

[15] Akkaya, Y., Peled, A., Picka, J.D. and Shah, S.P. 2000 Effect of sand addition on properties of fiber-reinforced cement composites, ACI Materials Journals, 97(3), pp. 393-400.

[16] Li, V.C. and Maalej, M. 1996 "Toughening in cement based composites, Part I: Cement, mortar and Concrete", Cement and Concrete Composite, 18, pp.223-237. 
Table 1 Experimental program and mix proportions: Part 1-Effect of hybrid fibres

\begin{tabular}{|c|c|c|c|c|c|c|c|c|}
\hline \multicolumn{2}{|c|}{ Series } & \multicolumn{3}{|c|}{$\begin{array}{l}\text { Fibre volume fractions } \\
(\%)\end{array}$} & \multicolumn{4}{|c|}{ Mix Proportions (by wt.) } \\
\hline & & \multirow[t]{2}{*}{$\mathrm{ST}^{\#}$} & \multirow{2}{*}{$\begin{array}{l}\mathrm{PE}^{\$} \\
(12 \mathrm{~mm})\end{array}$} & \multirow{2}{*}{$\begin{array}{l}\mathrm{PE} \\
(18 \mathrm{~mm})\end{array}$} & \multicolumn{2}{|l|}{ Binder } & \multirow[t]{2}{*}{ Water } & \multirow{2}{*}{$\begin{array}{l}\text { Super- } \\
\text { plasticizer }\end{array}$} \\
\hline & & & & & Cement & Silica fume & & \\
\hline \multirow[t]{4}{*}{1} & A & 1.8 & - & - & \multirow{26}{*}{0.9} & \multirow{26}{*}{0.1} & \multirow{26}{*}{0.27} & \multirow{26}{*}{0.02} \\
\hline & $\mathrm{B}$ & 2.0 & - & - & & & & \\
\hline & $\mathrm{C}$ & - & 1.8 & - & & & & \\
\hline & $\mathrm{D}$ & - & 2.0 & - & & & & \\
\hline \multirow[t]{6}{*}{2} & A & \multirow{6}{*}{0.5} & 0.2 & - & & & & \\
\hline & B & & 0.6 & - & & & & \\
\hline & $\mathrm{C}$ & & 0.8 & - & & & & \\
\hline & $\mathrm{D}$ & & 1.3 & - & & & & \\
\hline & $\mathrm{E}$ & & 1.5 & - & & & & \\
\hline & $\mathrm{F}$ & & 1.8 & - & & & & \\
\hline 3 & $\mathrm{~A}$ & \multirow{5}{*}{1.0} & 0.2 & - & & & & \\
\hline & $\mathrm{B}$ & & 0.4 & - & & & & \\
\hline & $\mathrm{C}$ & & 0.8 & - & & & & \\
\hline & $\mathrm{D}$ & & 1.0 & - & & & & \\
\hline & $\mathrm{E}$ & & 1.3 & - & & & & \\
\hline \multirow[t]{5}{*}{4} & A & \multirow{5}{*}{1.5} & 0.1 & - & & & & \\
\hline & $\mathrm{B}$ & & 0.2 & - & & & & \\
\hline & $\mathrm{C}$ & & 0.5 & - & & & & \\
\hline & $\mathrm{D}$ & & 0.8 & - & & & & \\
\hline & $\mathrm{E}$ & & 1.0 & - & & & & \\
\hline \multirow[t]{6}{*}{5} & A & 0.5 & - & 0.5 & & & & \\
\hline & B & 0.5 & - & 0.75 & & & & \\
\hline & $\mathrm{C}$ & 0.5 & - & 1.0 & & & & \\
\hline & $\mathrm{D}$ & 1.0 & - & 0.25 & & & & \\
\hline & $E$ & 1.0 & - & 0.55 & & & & \\
\hline & $\mathrm{F}$ & 1.5 & - & 0.35 & & & & \\
\hline
\end{tabular}

Note:

${ }^{\#}$ Steel fibre

${ }^{\$}$ Polyethylene fibre 
Table 2 Experimental program and mix proportions: Part 2-Effect of addition of sand

\begin{tabular}{|l|l|l|l|l|l|l|l|}
\hline \multirow{2}{*}{ Series } & \multicolumn{2}{|l|}{$\begin{array}{l}\text { Fibre volume } \\
\text { fractions (\%) }\end{array}$} & \multicolumn{2}{l|}{ Binder } & $\begin{array}{l}\text { Water/ } \\
\text { Binder }\end{array}$ & $\begin{array}{l}\text { Sand/ } \\
\text { Binder }\end{array}$ & $\begin{array}{l}\text { Super- } \\
\text { plasticizer }\end{array}$ \\
\cline { 2 - 5 } & ST & PE & Cement & Silica fume & & & \\
\hline 1 & 0.5 & 1.3 & 0.9 & 0.1 & 0.4 & 0.5 & 0.02 \\
\hline 2 & 1.0 & 0.8 & 0.9 & 0.1 & 0.4 & 0.5 & 0.02 \\
\hline 3 & 1.5 & 0.5 & 0.9 & 0.1 & 0.4 & 0.5 & 0.02 \\
\hline
\end{tabular}

Table 3 Physical Properties and Chemical Composition of Cementitious Materials

\begin{tabular}{|c|c|c|}
\hline Properties & $\mathrm{OPC}$ & SF \\
\hline Type/ class & ASTM Type I & - \\
\hline $\begin{array}{l}\text { Physical Properties: } \\
\text { Specific Gravity } \\
\text { Fineness } \\
\qquad \begin{array}{l}\text { Passing } 45 \mu \mathrm{m} \text { sieve }(\%) \\
\text { Retained on } 150 \mu \mathrm{m} \text { sieve }(\%) \\
\text { Surface area, Blaine }\left(\mathrm{cm}^{2} / \mathrm{gm}\right)\end{array}\end{array}$ & $\begin{array}{c}3.17 \\
- \\
- \\
3170\end{array}$ & $\begin{array}{c}2.00 \\
- \\
- \\
250000\end{array}$ \\
\hline $\begin{array}{l}\text { Chemical Analysis: } \\
\mathrm{SiO}_{2} \\
\mathrm{Al}_{2} \mathrm{O}_{3} \\
\mathrm{Fe}_{2} \mathrm{O}_{3} \\
\mathrm{CaO} \\
\mathrm{MgO} \\
\mathrm{SO}_{3} \\
\mathrm{Na}_{2} \mathrm{O} \\
\mathrm{K}_{2} \mathrm{O} \\
\mathrm{LOI}\end{array}$ & $\begin{array}{c}21.10 \\
5.24 \\
3.10 \\
64.39 \\
1.10 \\
2.52 \\
0.23 \\
0.57 \\
1.22\end{array}$ & $\begin{array}{c}93.0 \\
0.2 \\
0.05 \\
- \\
0.51 \\
0.05 \\
0.2 \\
0.22 \\
4.15\end{array}$ \\
\hline
\end{tabular}

Note: OPC: Ordinary Portland cement; SF: Silica Fume

Table 4 Properties of fibres

\begin{tabular}{|c|c|c|c|c|c|}
\hline Fibre types & $\begin{array}{c}\text { Length } \\
\mathrm{mm}\end{array}$ & $\begin{array}{c}\text { Diameter } \\
\mu \mathrm{m}\end{array}$ & $\begin{array}{c}\text { Modulus of } \\
\text { elasticity } \\
\mathrm{GPa}\end{array}$ & $\begin{array}{c}\text { Fibre strength, } \\
\mathrm{MPa}\end{array}$ & $\begin{array}{c}\text { Fibre } \\
\text { density } \\
\mathrm{gm} / \mathrm{cm}^{3}\end{array}$ \\
\hline Steel & 13 & 160 & 200 & 2500 & 7.8 \\
\hline PE & 12 and 18 & 39 & 79 & 2610 & 0.97 \\
\hline
\end{tabular}




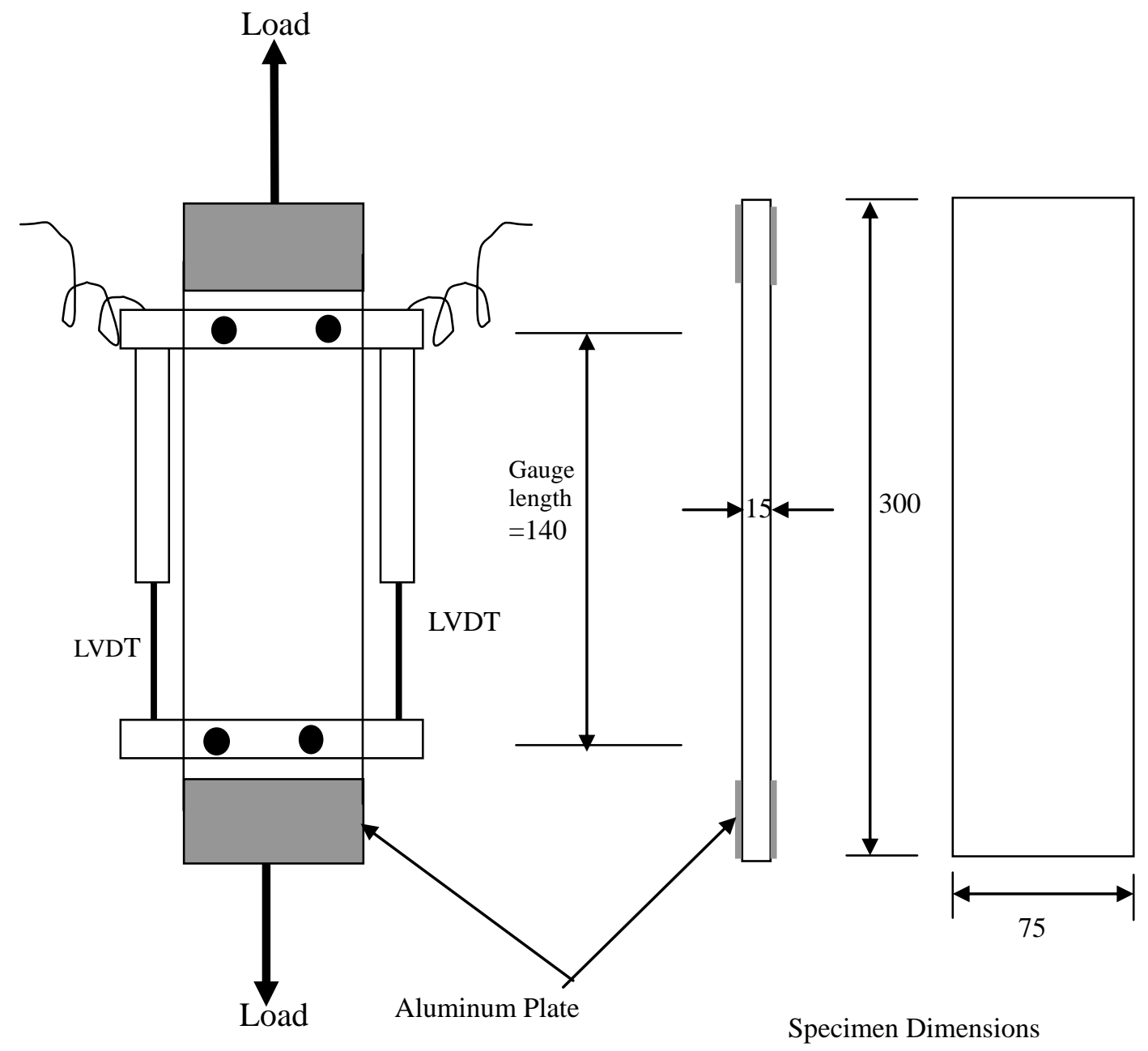

Fig. 1 Uni-axial tension test setup (All dimensions are in $\mathrm{mm}$ ) 


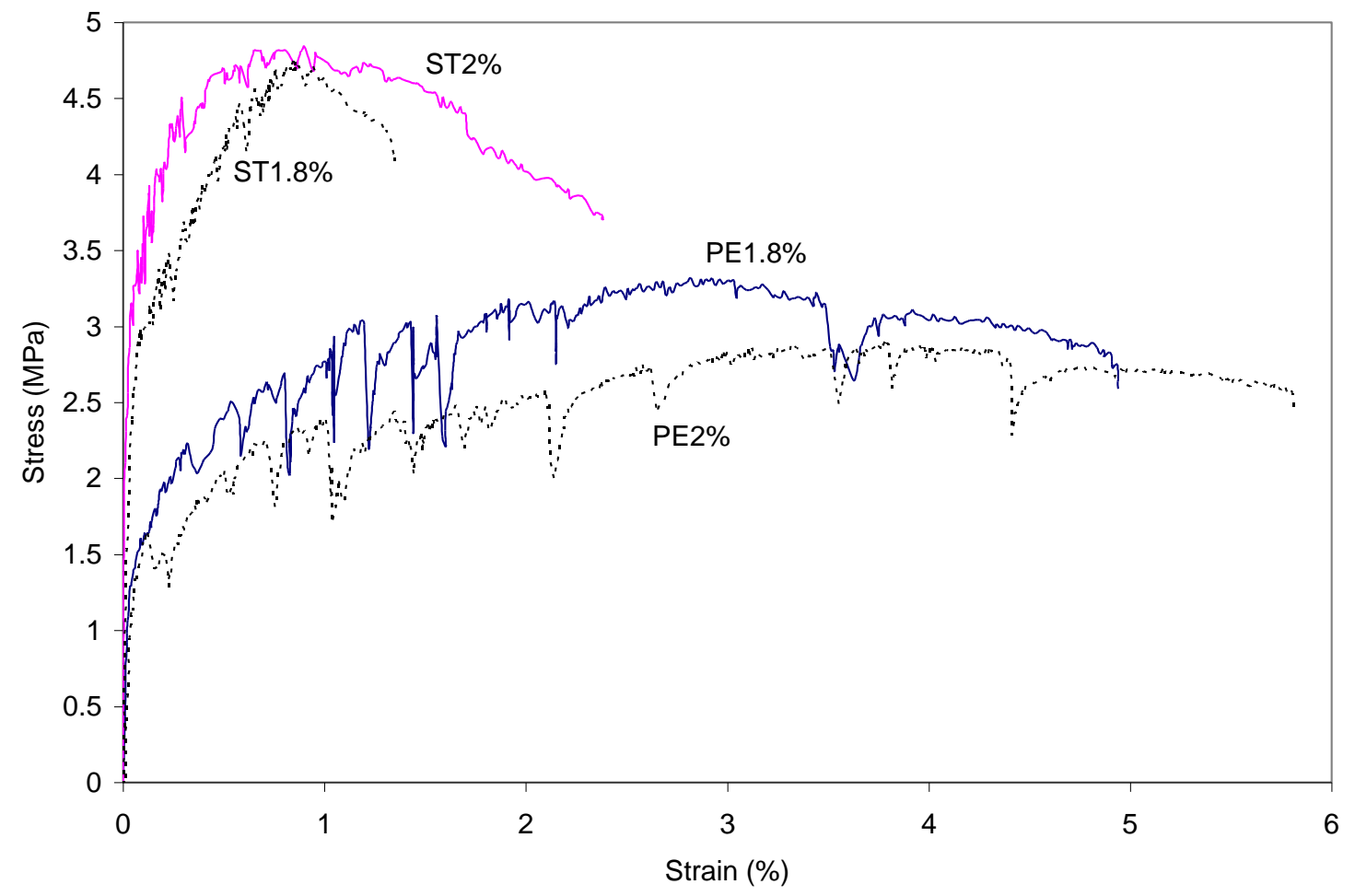

Fig. 2 Tensile strain hardening behaviour of mono fibre composites

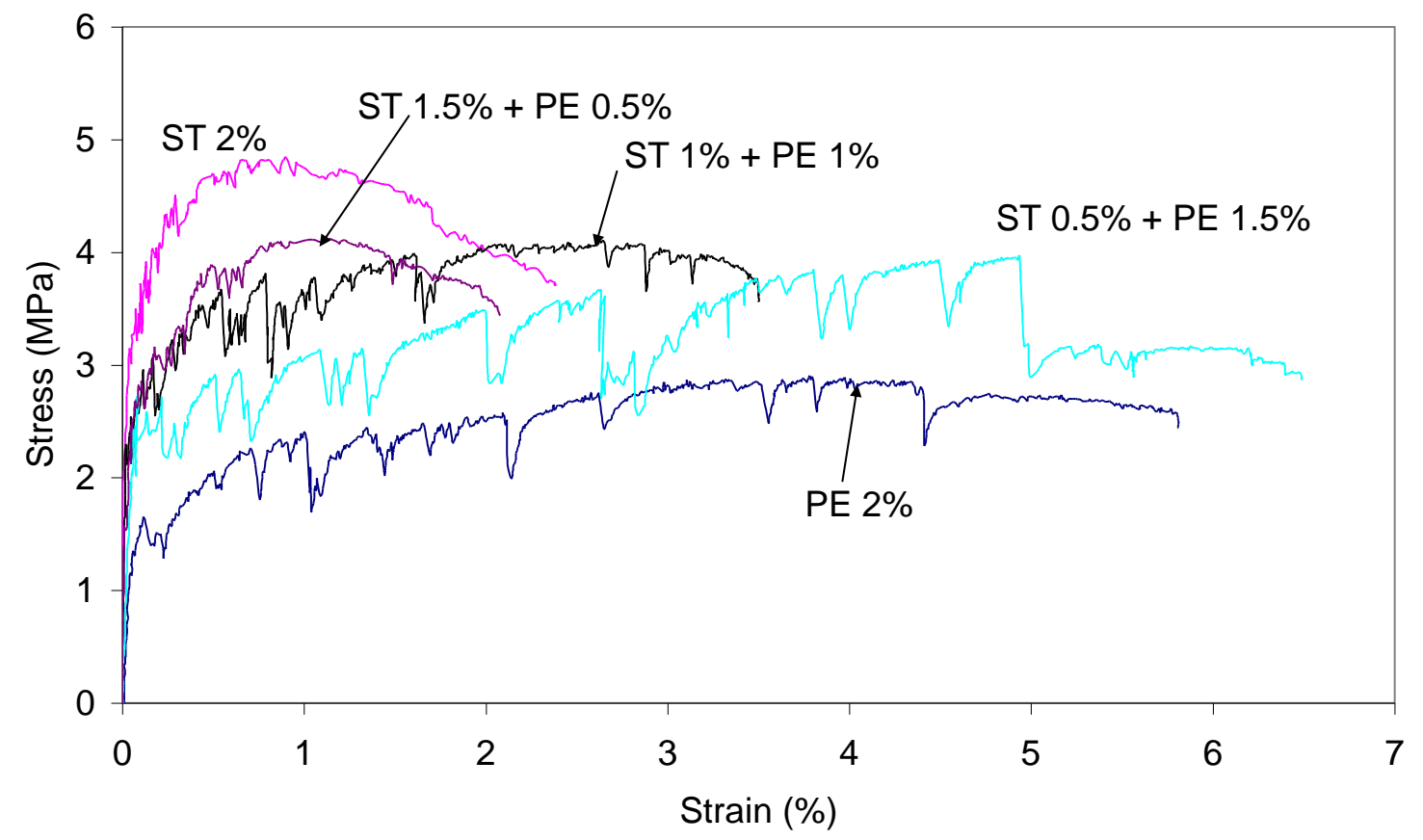

Fig. 3 Effect of hybrid reinforcement 


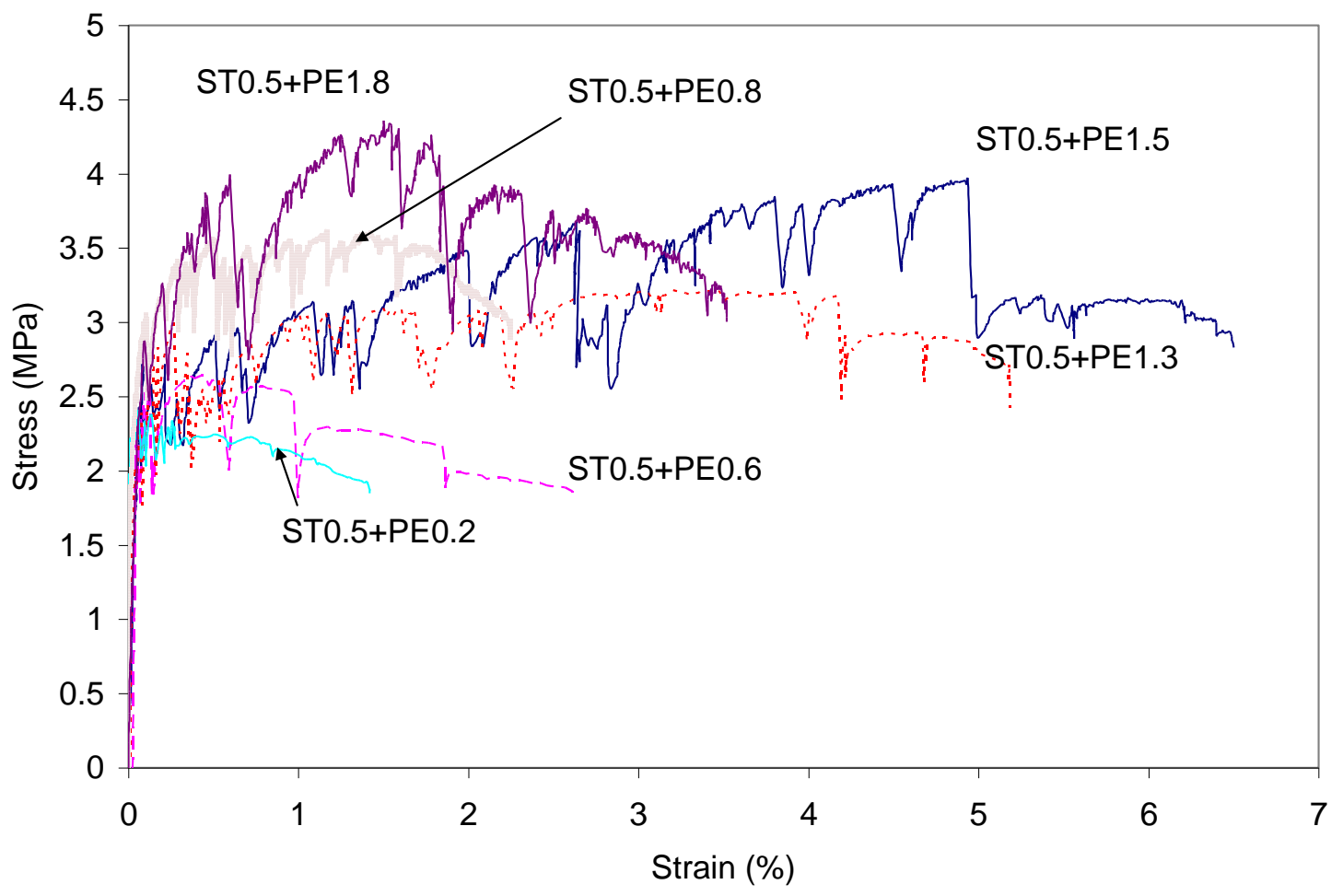

Fig. 4 Tensile strain hardening behaviour of hybrid fibre composites containing $0.5 \%$ steel (ST) fibres and different volume fractions of PE fibres 


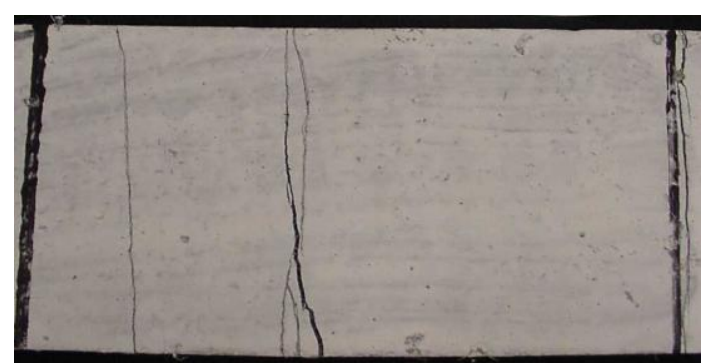

(a) ST0.5+PE0.2

[3]

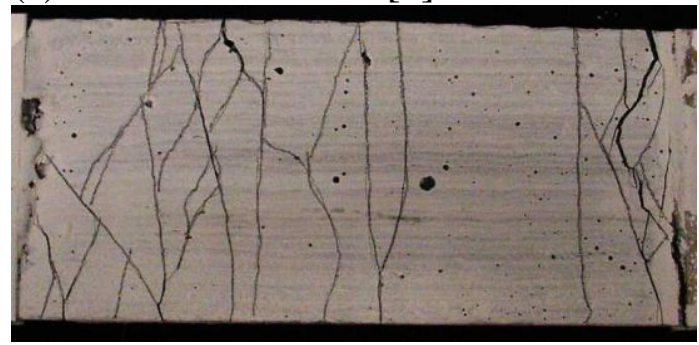

(c) ST0.5+PE0.8

[17]

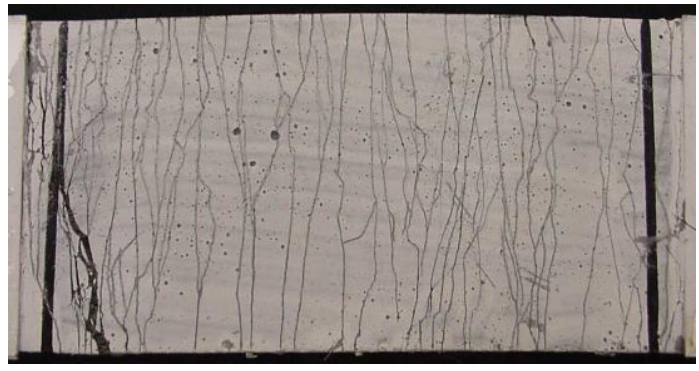

(e) ST0.5+PE1.5

[39]

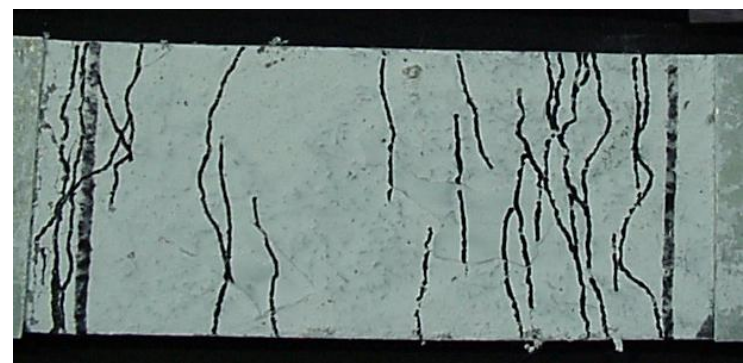

(b) ST0.5+PE0.6

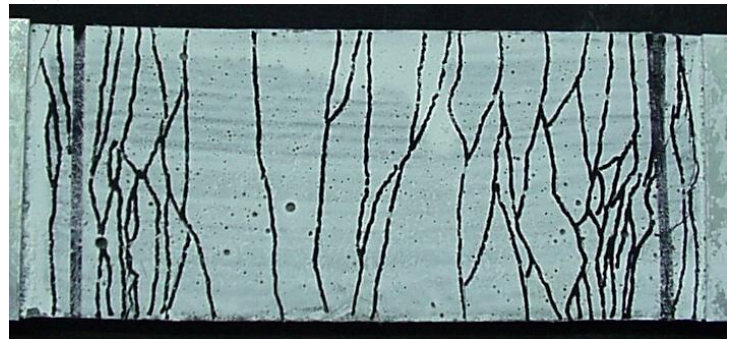

(d) ST0.5+PE1.3

$[25]$

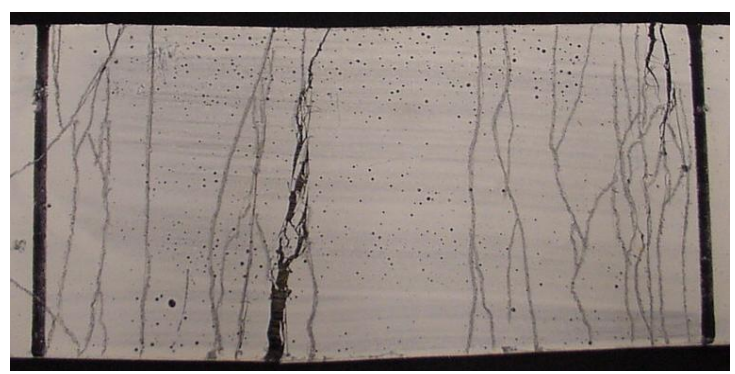

(f) ST0.5+PE1.8

Fig. 5 Multiple cracking behaviour of hybrid fibre composites containing $0.5 \%$ steel (ST) fibres and different volume fractions of PE fibres. (Number of multiple cracks is shown in square brackets [ ])
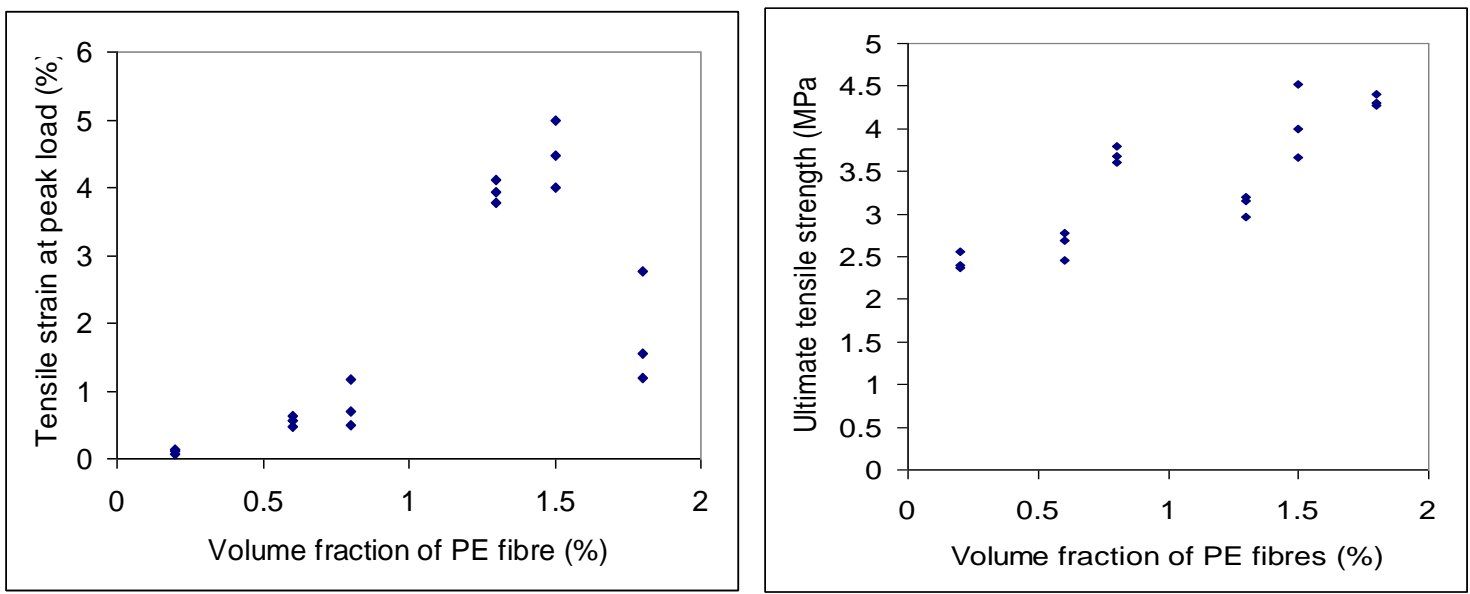

Fig. 6 Effect of PE fibre contents on the tensile strain capacity at peak load and ultimate tensile strength of hybrid fibre composites containing $0.5 \%$ ST fibres and different volume fractions of PE fibres. 


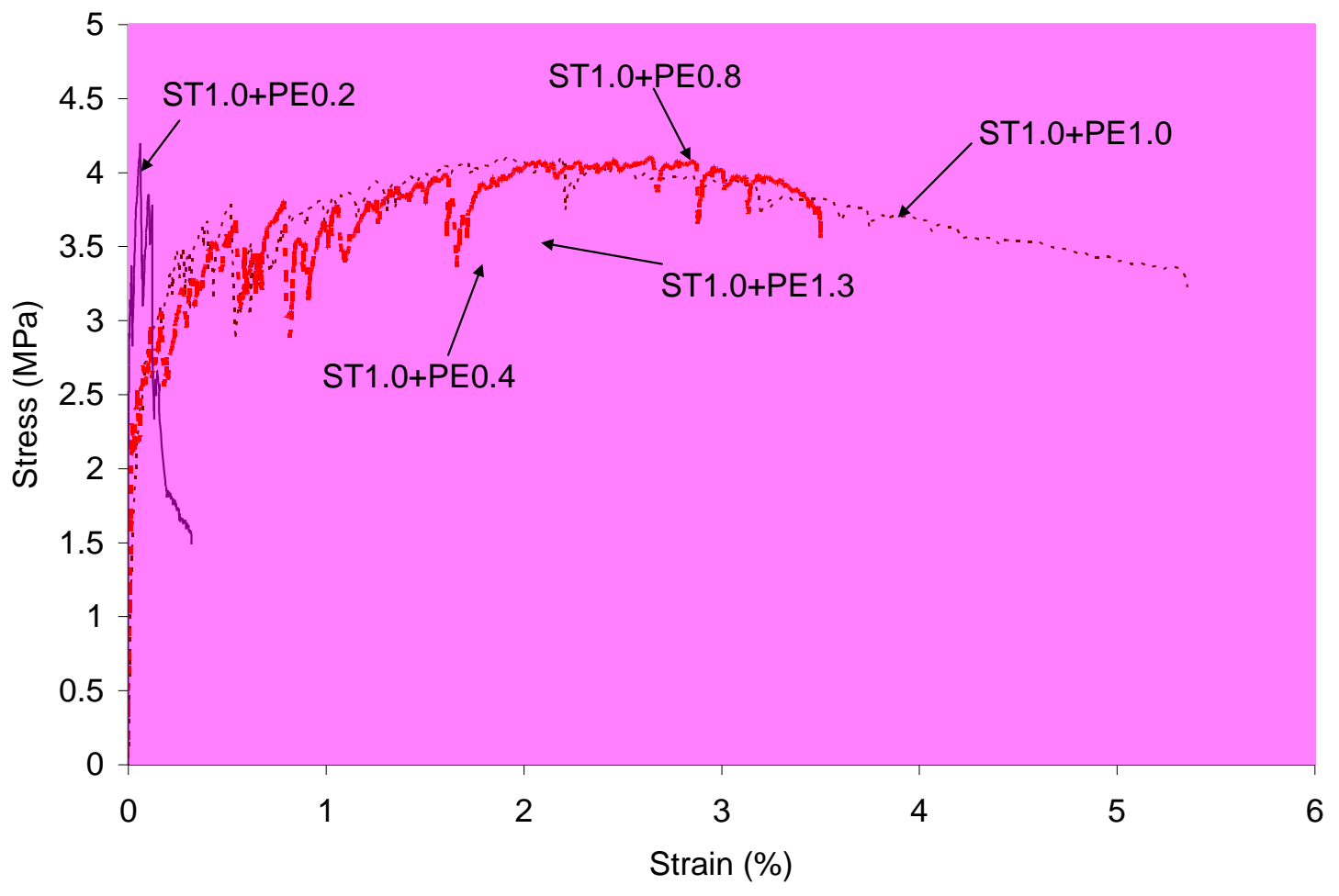

Fig.7 Tensile strain hardening behaviour of hybrid fibre composites containing 1.0\% steel (ST) fibres and different volume fractions of PE fibres 

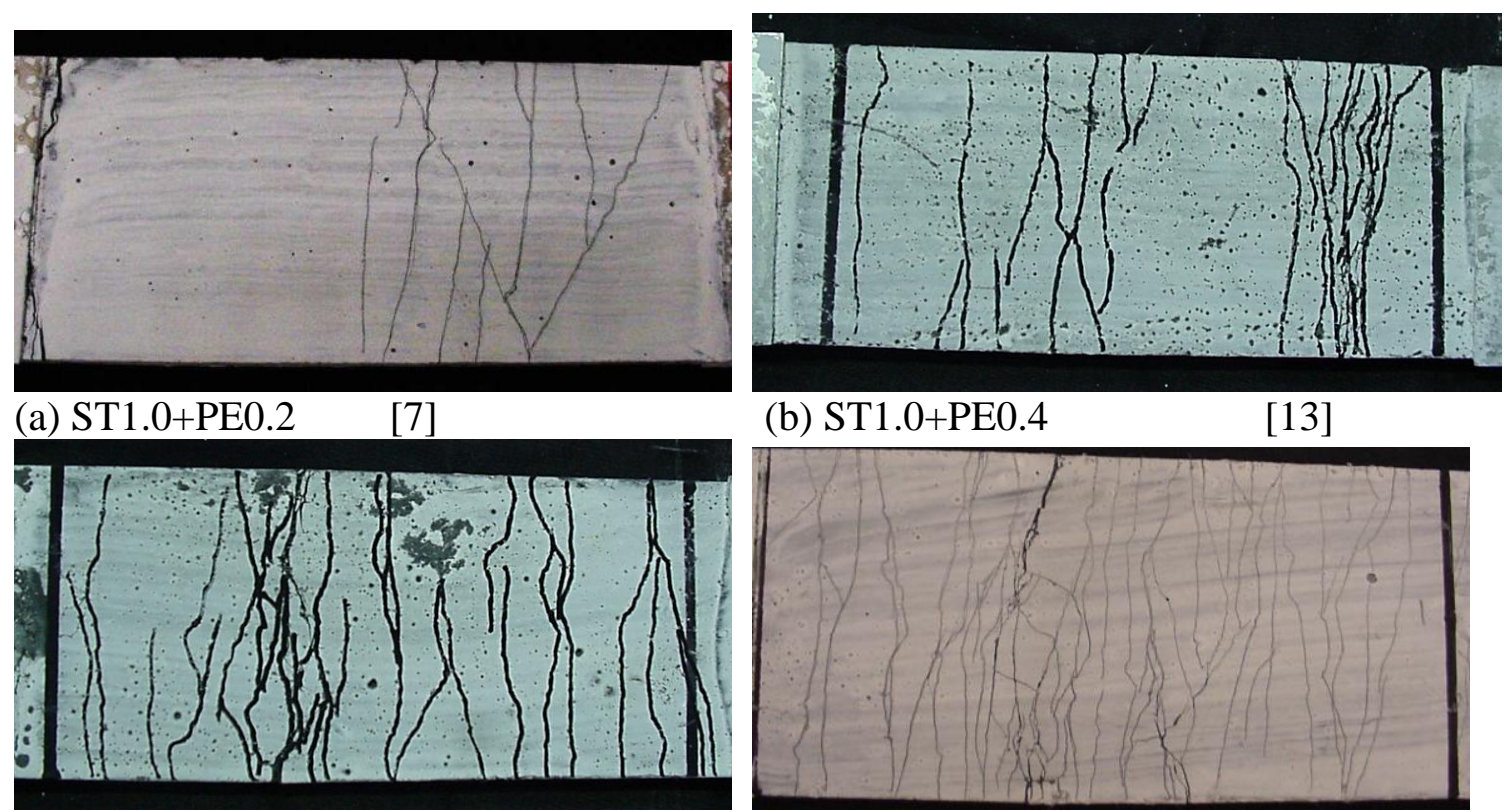

(c) ST1.0+PE0.8

[22]

(b) ST1.0+PE0.4

[13]

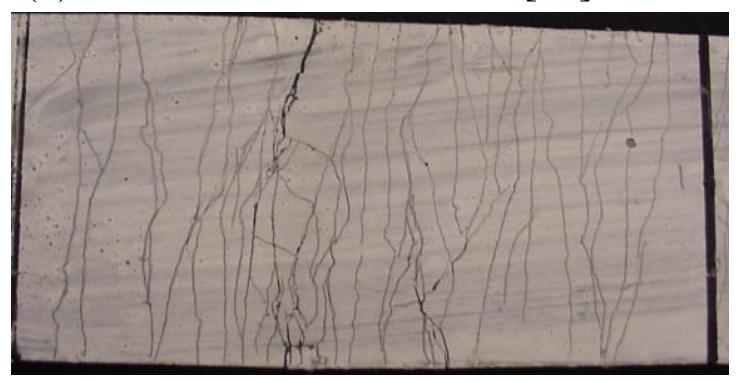

(d) ST1.0+PE1.0

[29]

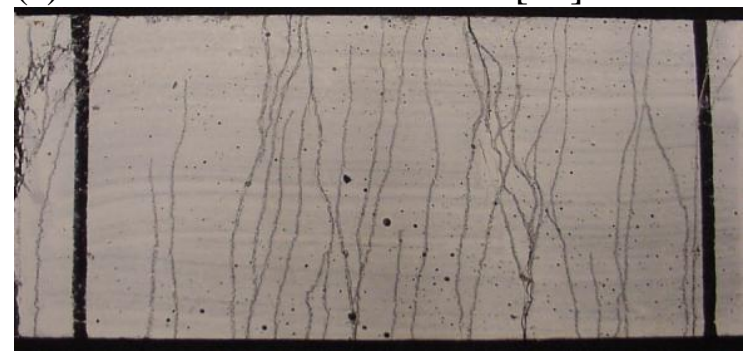

[21]

(e) ST1.0+PE1.3

Fig. 8 Multiple cracking behaviour of hybrid fibre composites containing $1.0 \%$ steel (ST) fibres and different volume fractions of PE fibres. (Number of multiple cracks is shown in square brackets [ ])
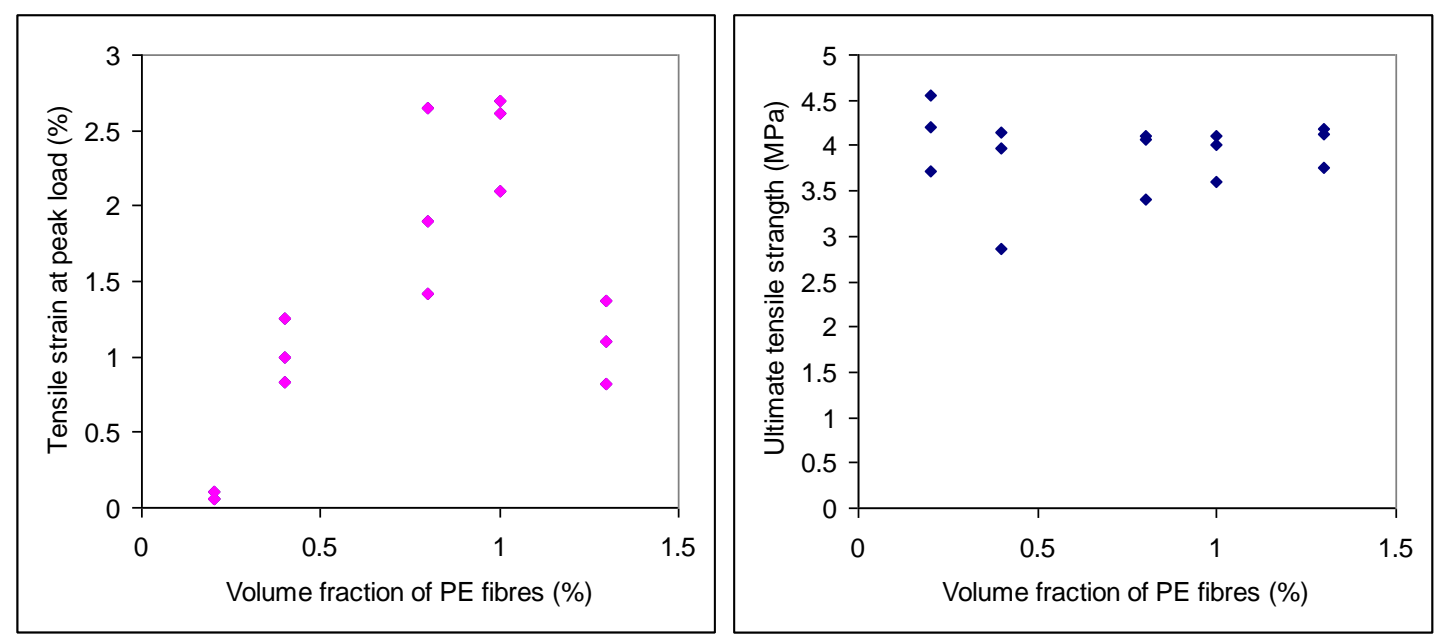

Fig. 9 Effect of PE fibre contents on the tensile strain capacity at peak load and ultimate tensile strength of hybrid fibre composites containing $1.0 \%$ ST fibres and different volume fractions of PE fibres. 


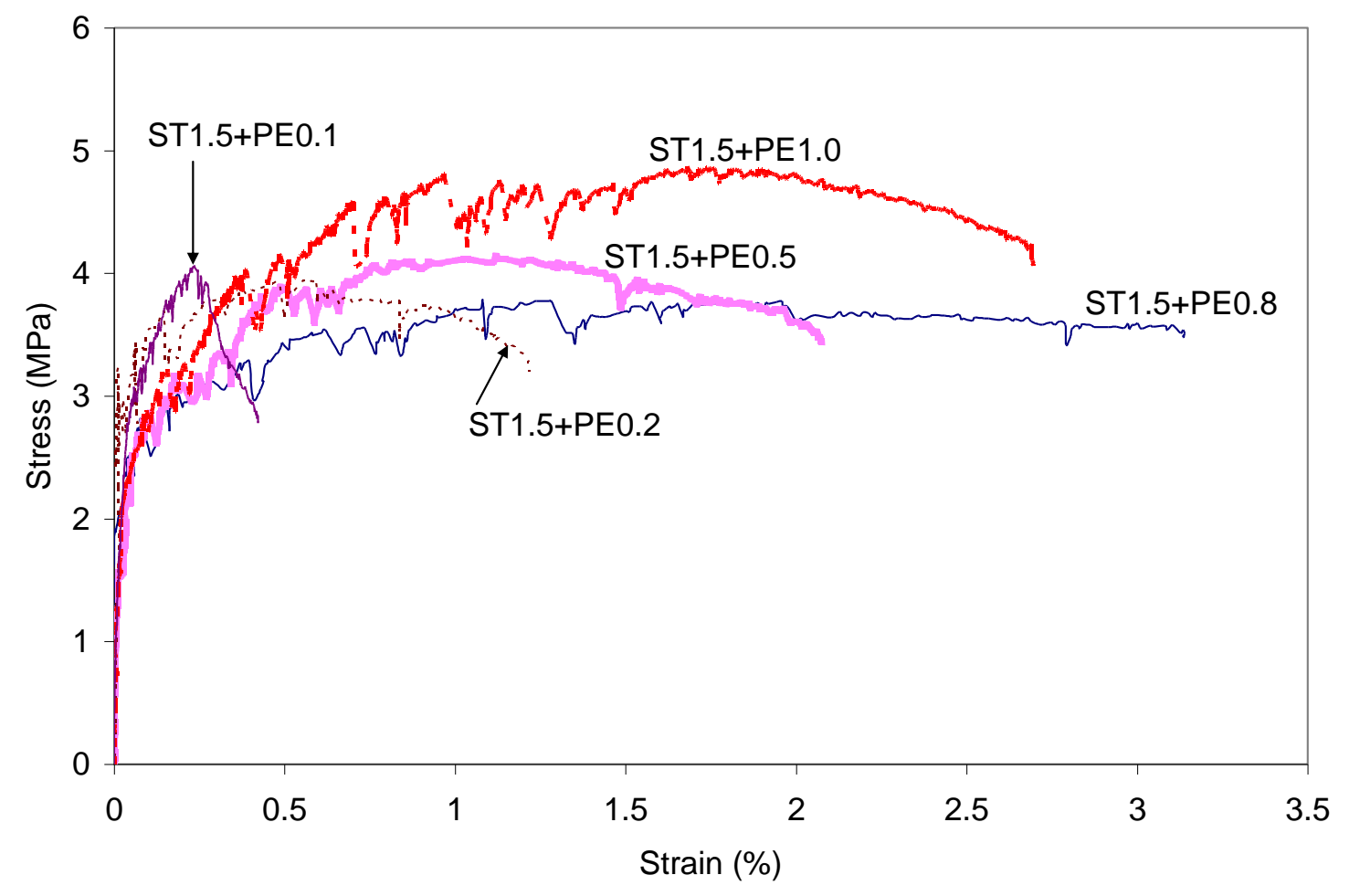

Fig.10 Tensile strain hardening behaviour of hybrid fibre composites containing 1.5\% steel (ST) fibres and different volume fractions of PE fibres 


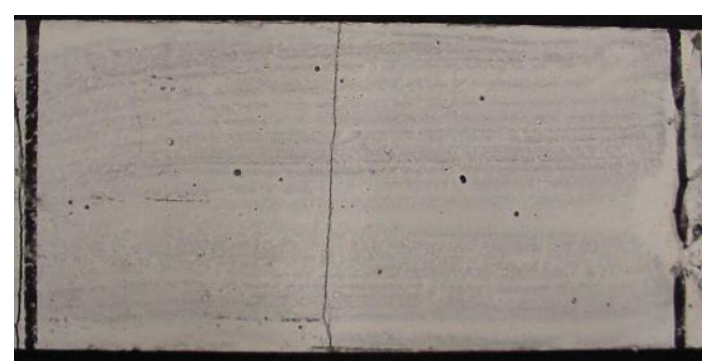

(a) ST1.5+PE0.1

[1]

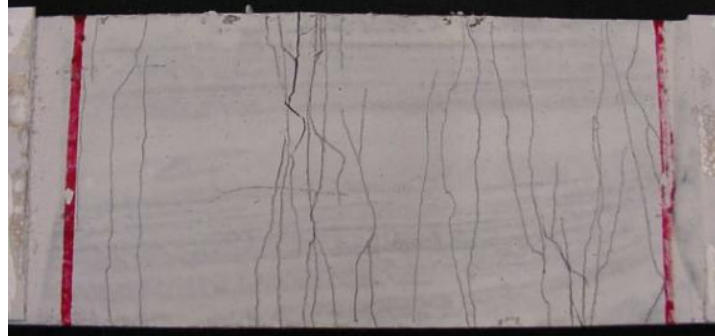

(c) ST1.5+PE0.5

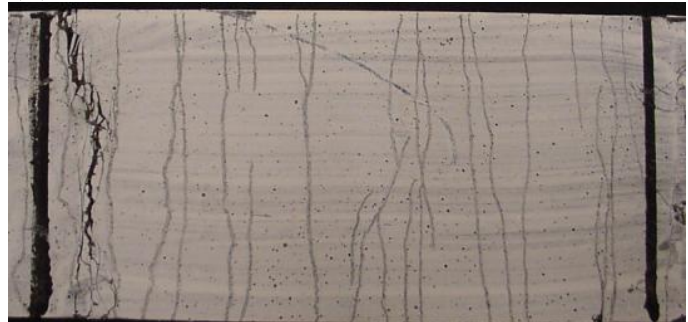

(e) ST1.5+PE1.0

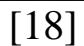

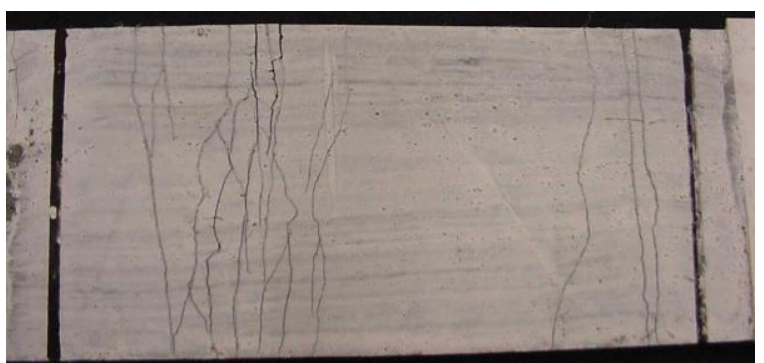

(b) ST1.5+PE0.2

[12]

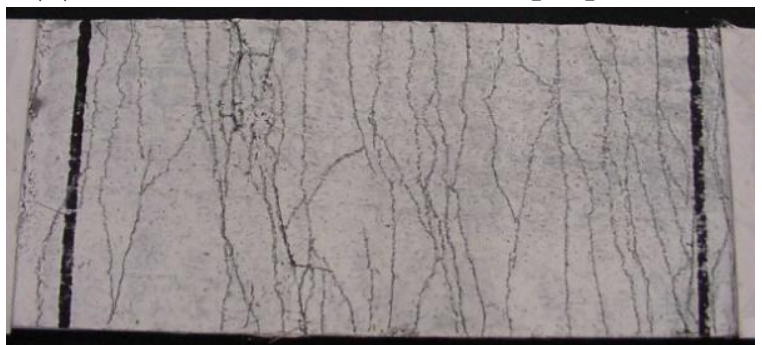

(d) ST1.5+PE0.8

$[28]$

Fig. 11 Multiple cracking behaviour of hybrid fibre composites containing $1.5 \%$ steel (ST) fibres and different volume fractions of PE fibres. (Number of multiple cracks is shown in square brackets [ ])
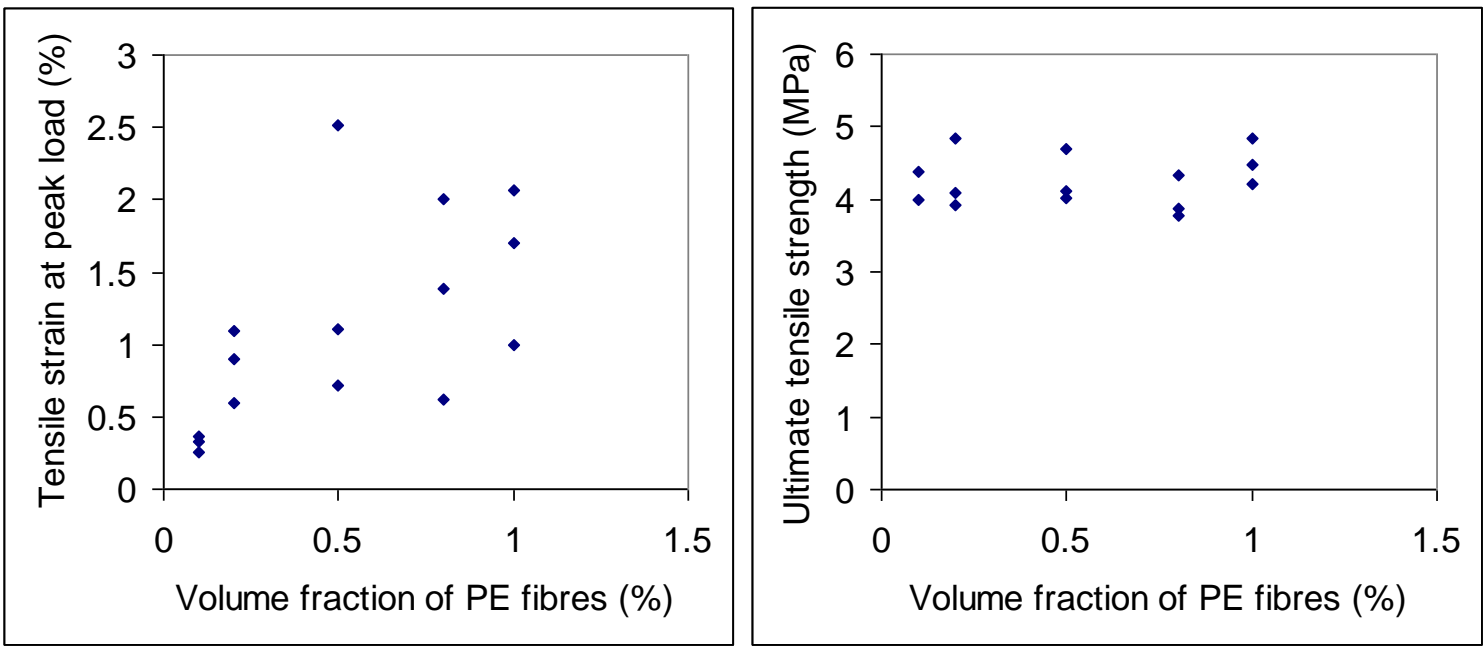

Fig. 12 Effect of PE fibre contents on the tensile strain capacity at peak load and ultimate tensile strength of hybrid fibre composites containing 1.5\% ST fibres and different volume fractions of PE fibres. 

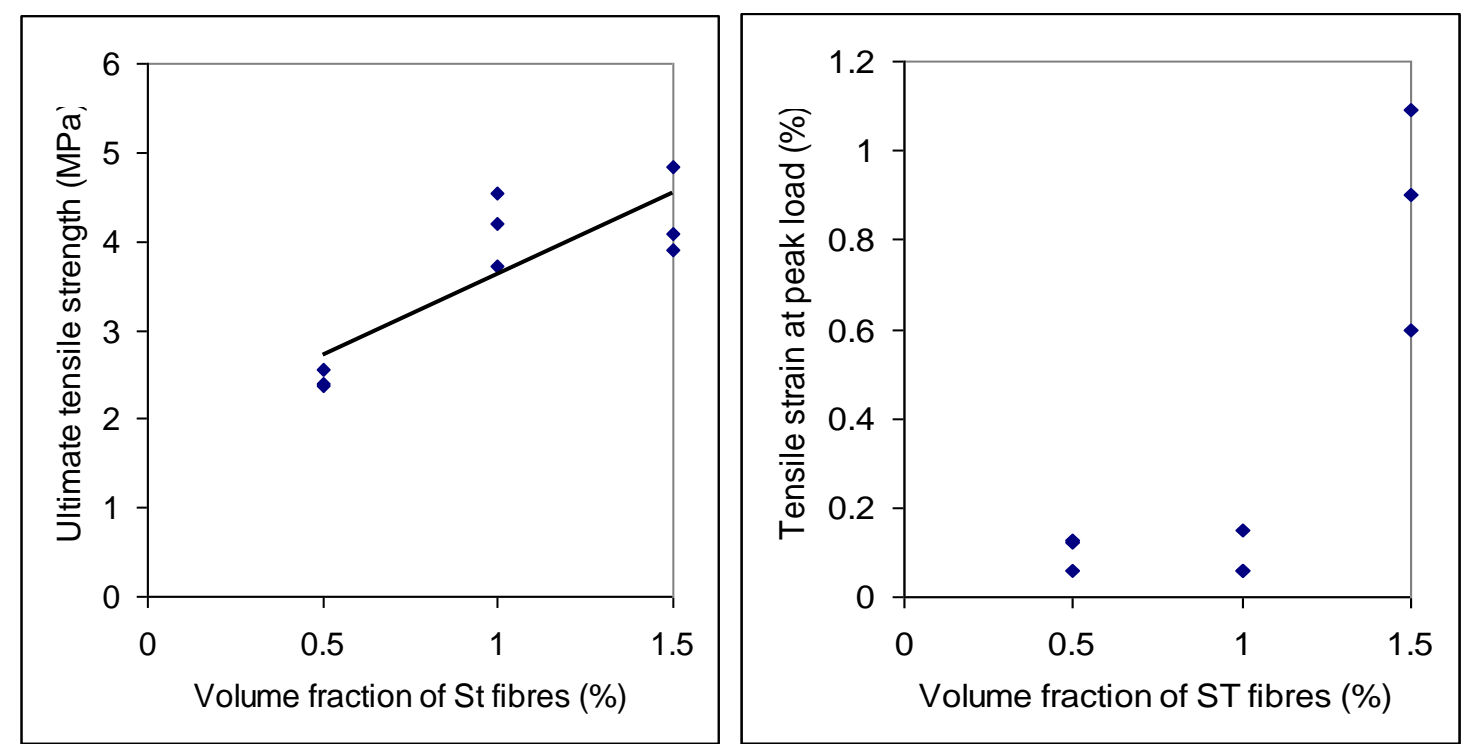

Fig. 13 Effect of ST fibres content on the ultimate tensile strength and strain capacity at peak load of hybrid fibres composites containing $0.2 \% \mathrm{PE}$ and different volume fractions of ST fibres.
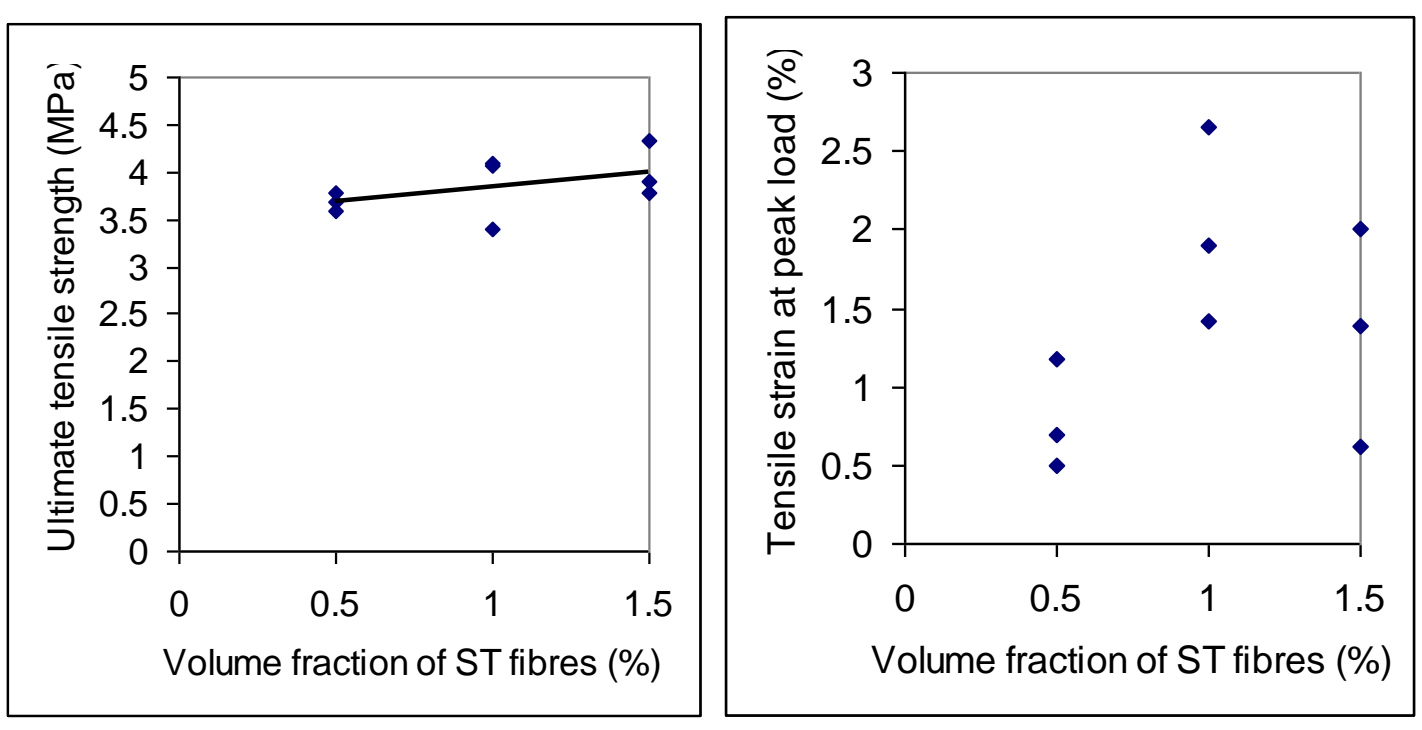

Fig. 14 Effect of ST fibres content on the ultimate tensile strength and strain capacity at peak load of hybrid fibres composites containing $0.8 \% \mathrm{PE}$ and different volume fractions of ST fibres. 


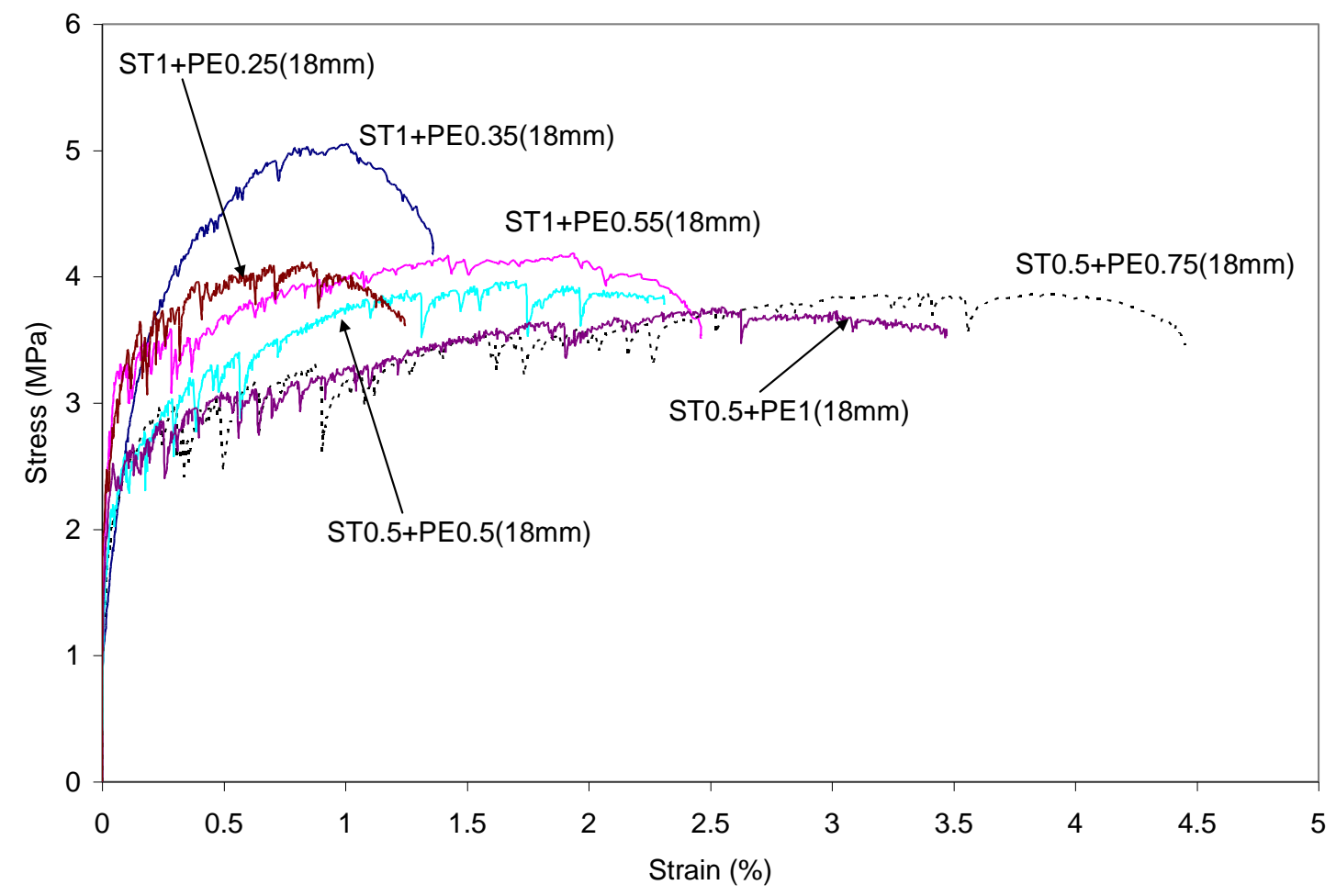

Fig. 15 Tensile strain hardening behaviour of hybrid fibre composites containing different volume fractions of ST and PE fibres of $18 \mathrm{~mm}$ length.

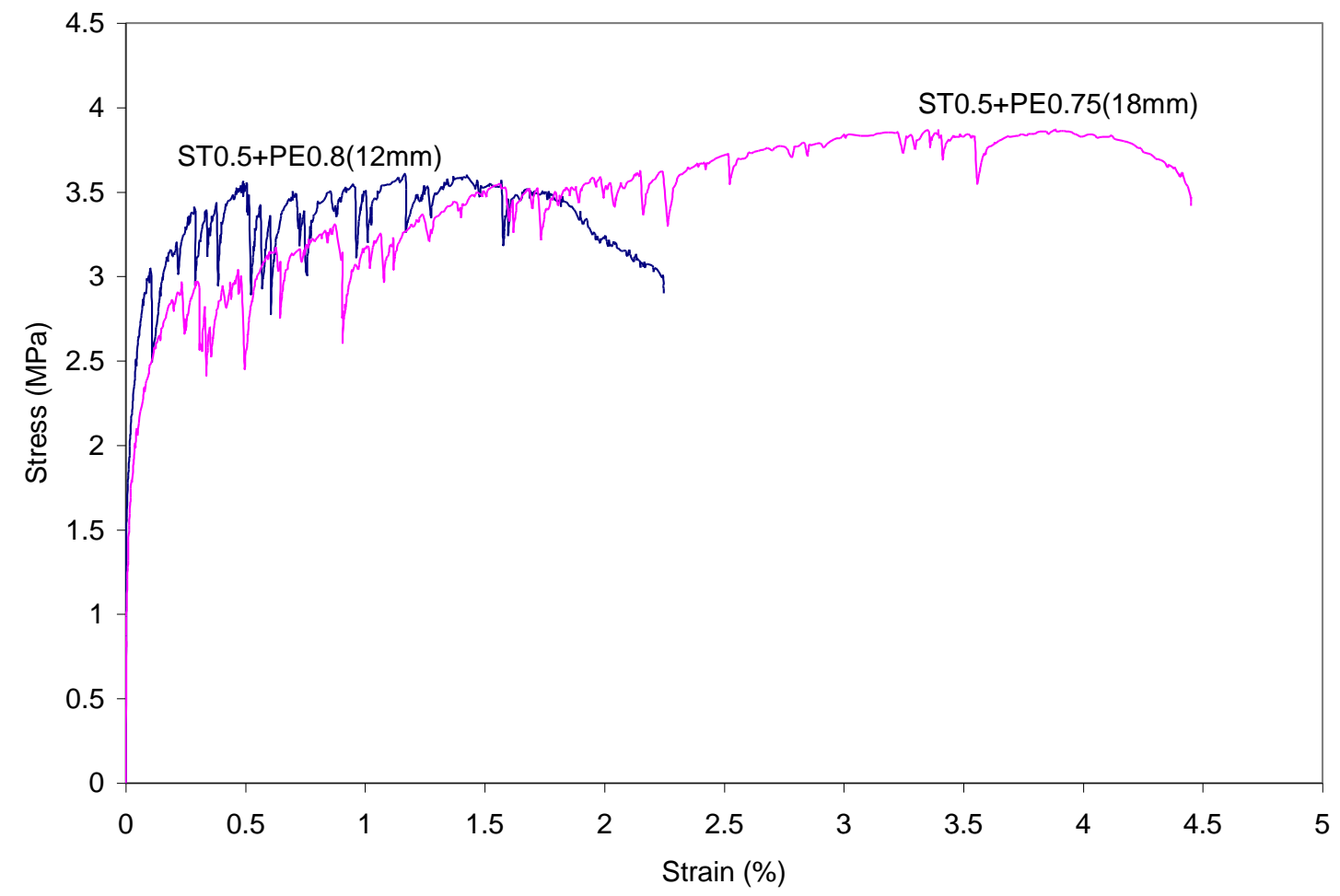

Fig. 16 Effect of increase of length of PE fibre on the tensile strain hardening behaviour of hybrid fibre composites. 


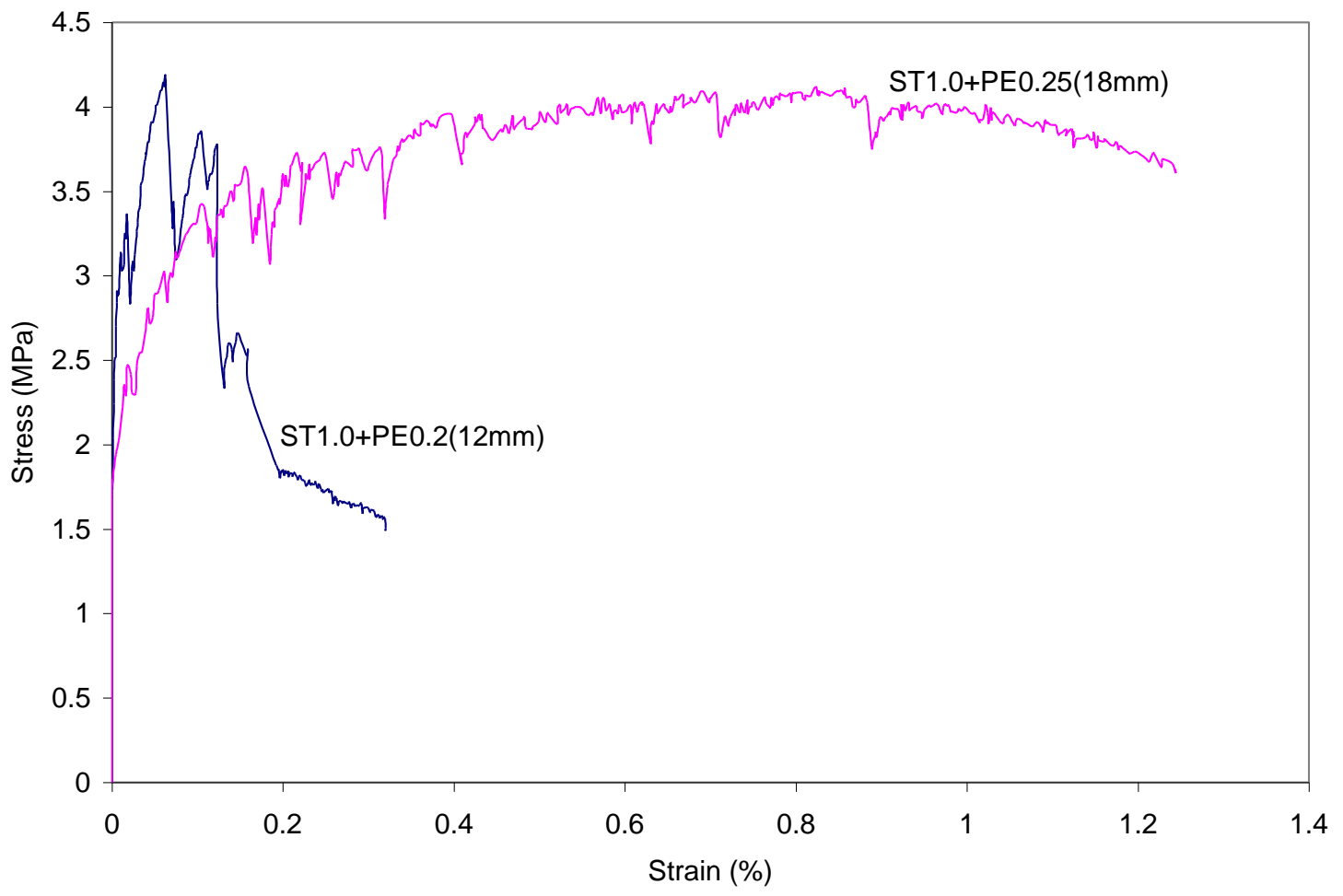

Fig. 17 Effect of increase of length of PE fibre on the tensile strain hardening behaviour of hybrid fibre composites 


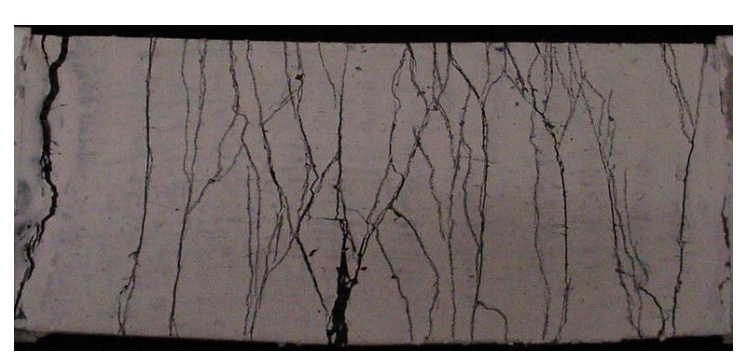

(a) ST0.5+PE0.5 (18mm)

[22]

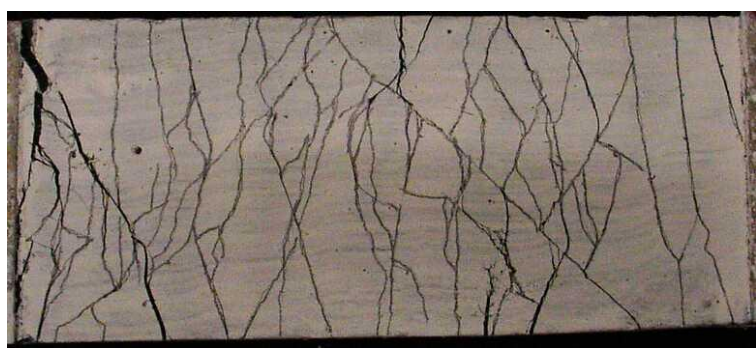

(c) ST0.5+PE1.0 (18mm)

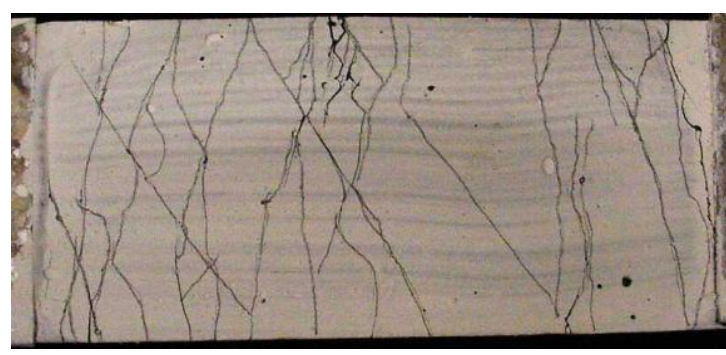

(d) ST1.0+PE0.25 (18mm)
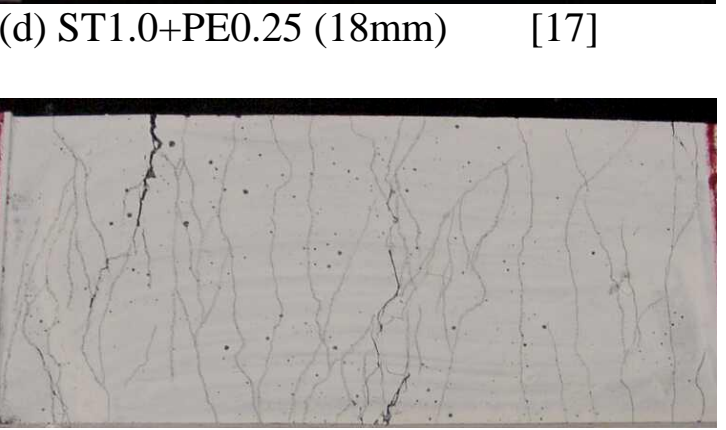

(f) ST1.5+PE0.35 (18mm)

[26]

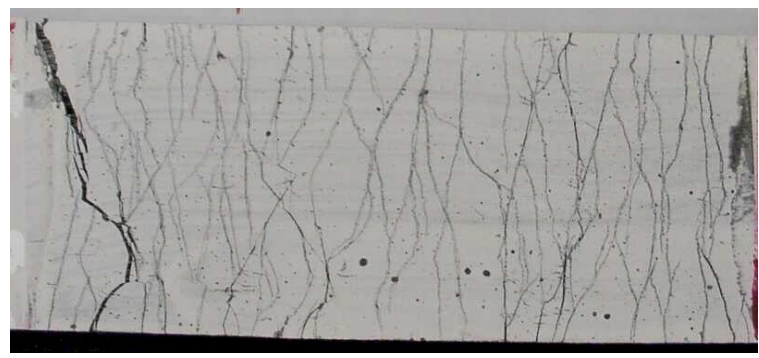

(b) ST0.5+PE0.75 (18mm)

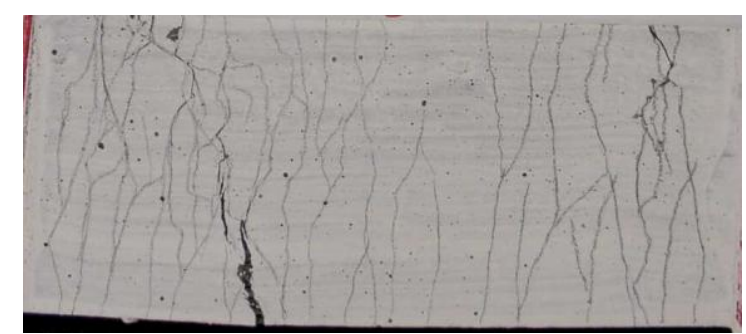

(e) ST1.0+PE0.55 (18mm)

[29]

Fig. 18 Multiple cracking behaviour of hybrid fibre composites containing different volume fractions of ST and PE fibres of $18 \mathrm{~mm}$ length. (Number of multiple cracks is shown in square brackets []) 
(a)

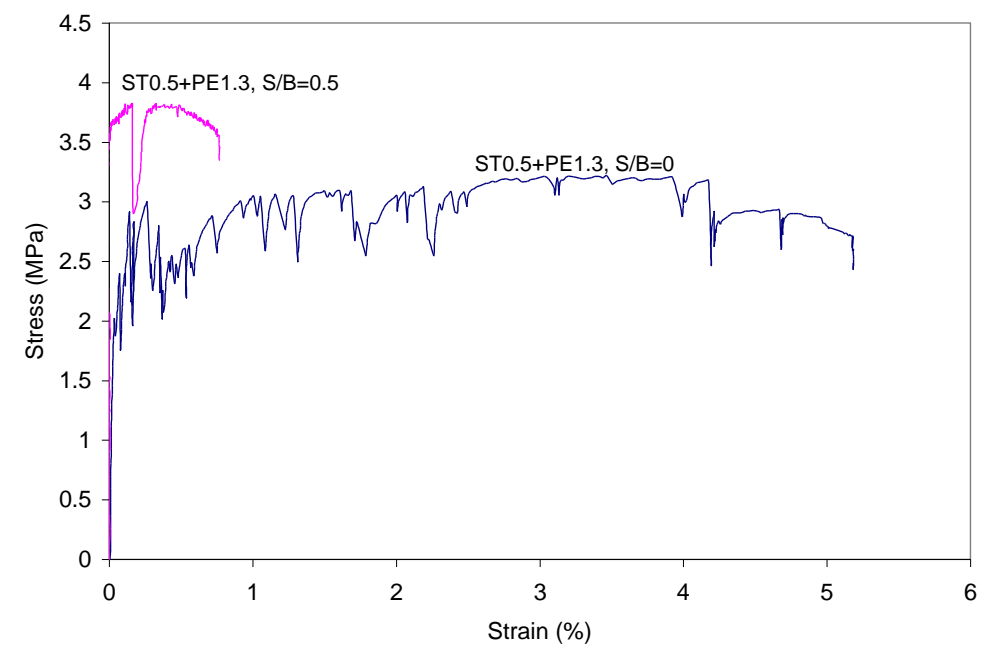

(b)

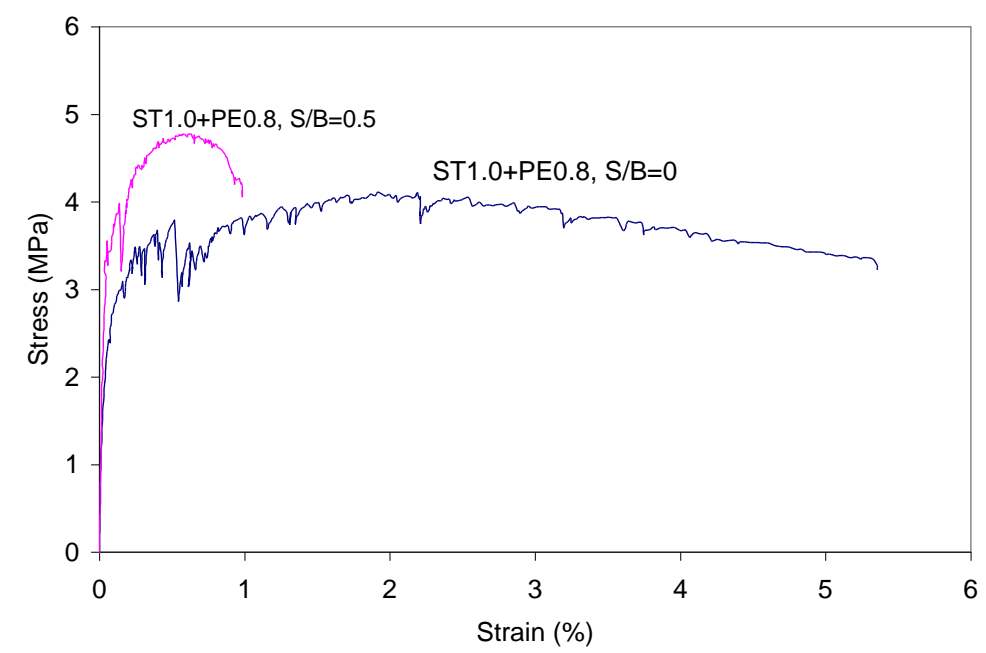

(c)

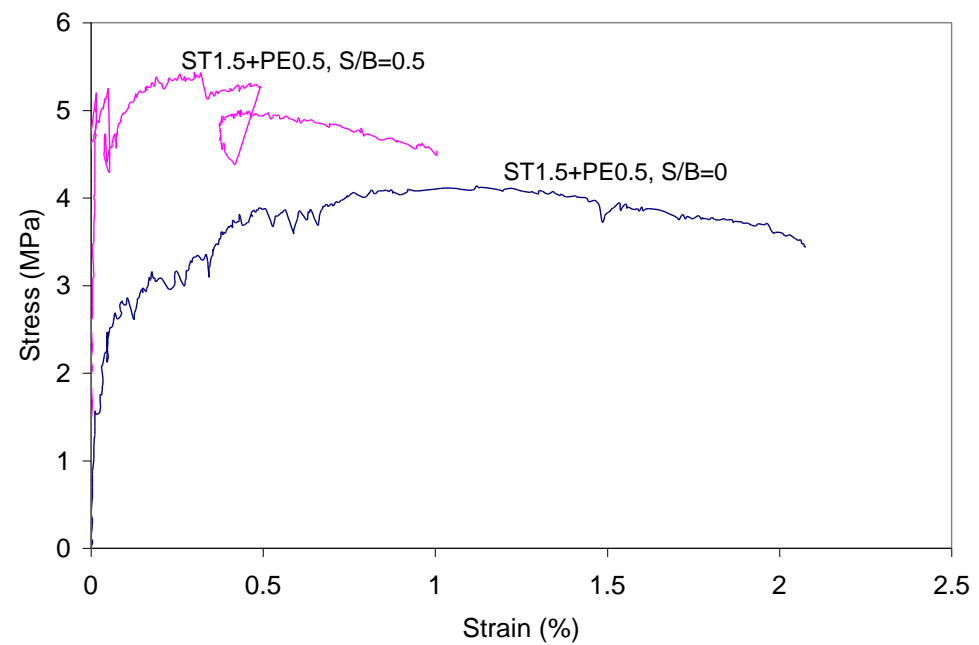

Fig. 19 Effect of addition of sand of 425 micrometer in size on the tensile strain hardening behaviour of different hybrid ST-PE fibre composites 


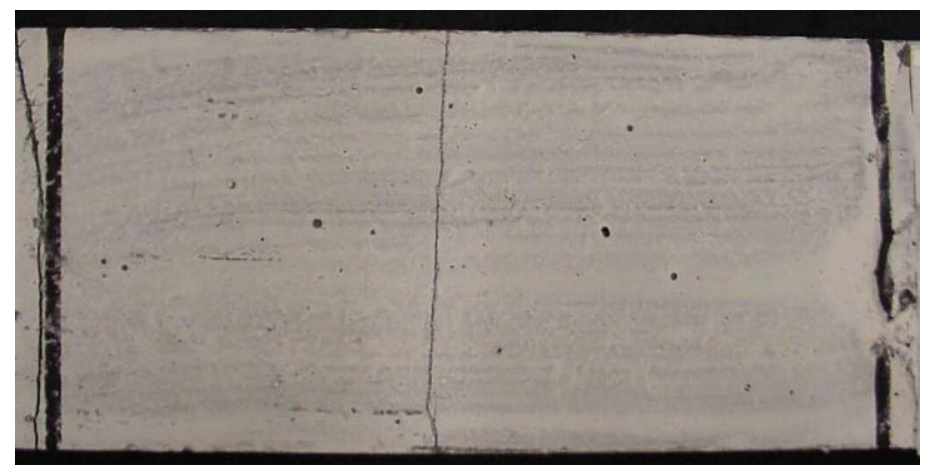

(a) ST0.5+PE1.3

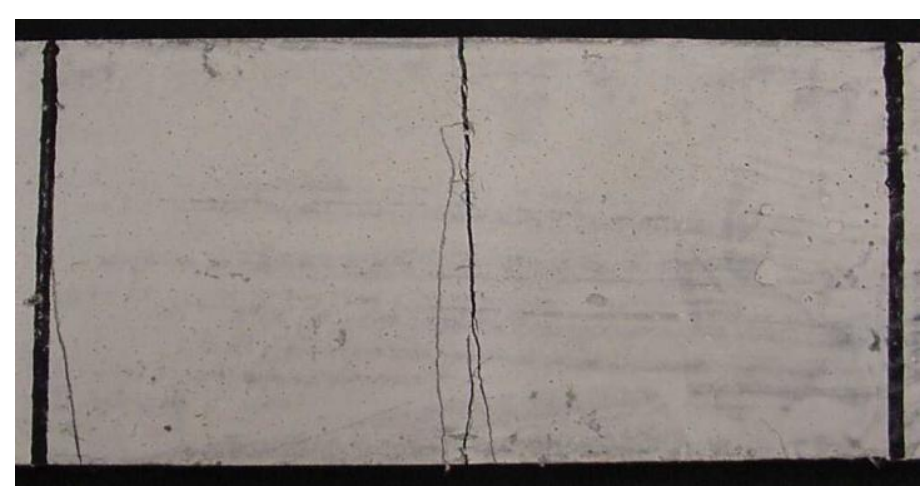

(b) ST1.0+PE0.8

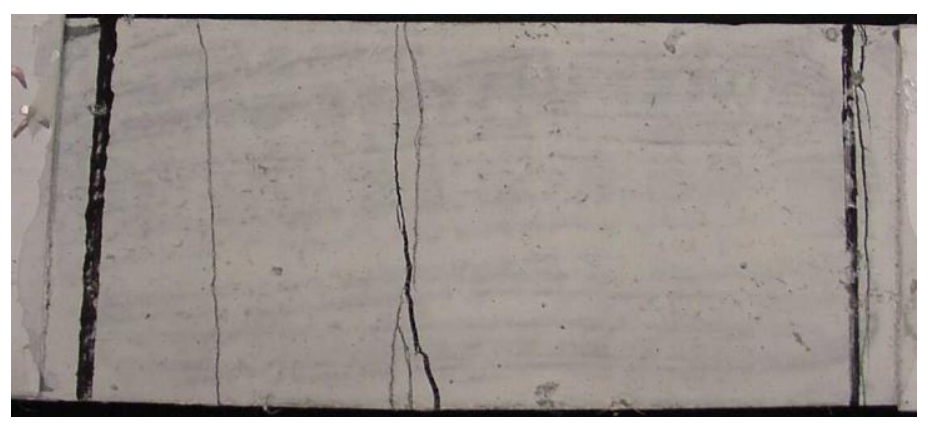

(c) ST1.5+PE0.5

Fig. 20 Cracking behaviour of different hybrid composites containing 425 micrometer sand with sand/binder ratio 0.5 . 